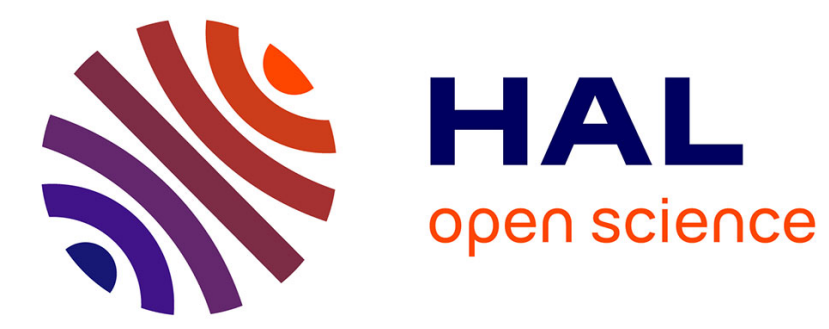

\title{
Demographic Ageing in the Mediterranean: The End of the Spatial Dichotomy Between the Shores?
}

\author{
Yoann Doignon
}

\section{To cite this version:}

Yoann Doignon. Demographic Ageing in the Mediterranean: The End of the Spatial Dichotomy Between the Shores?. Spatial Demography, 2019, 10.1007/s40980-019-00054-2 . hal-02296528

\section{HAL Id: hal-02296528 \\ https://hal.science/hal-02296528}

Submitted on 25 Sep 2019

HAL is a multi-disciplinary open access archive for the deposit and dissemination of scientific research documents, whether they are published or not. The documents may come from teaching and research institutions in France or abroad, or from public or private research centers.
L'archive ouverte pluridisciplinaire HAL, est destinée au dépôt et à la diffusion de documents scientifiques de niveau recherche, publiés ou non, émanant des établissements d'enseignement et de recherche français ou étrangers, des laboratoires publics ou privés. 


\title{
Demographic ageing in the Mediterranean: the end of the spatial dichotomy between the shores?
}

\author{
Yoann Doignon ${ }^{1,2}$ \\ ${ }^{1}$ Aix Marseille Univ, CNRS, LAMES, UMR 7305, Aix-en-Provence, France \\ ${ }^{2}$ Aix Marseille Univ, Université Côte d'Azur, Avignon Université, CNRS, UMR 7300 Avignon, France \\ yoann.doignon@uclouvain.be
}

\begin{abstract}
The Mediterranean is too often presented as a heterogeneous geographical area. Demography has helped to create this narrative of a Mediterranean of contrasts in which the different shores are systematically opposed: a northern shore in decline, with low fertility rates and an ageing population, as opposed to the young and fertile southern and eastern shores, which are experiencing rapid growth. However, this spatial dichotomy is gradually disappearing due to demographic transition: population growth and fertility are in decline, and the disparities between the different areas of the Mediterranean are vanishing. Moreover, demographic transition automatically gives rise to an ageing population. While the varied populations of the Mediterranean are currently differentiated by their levels of ageing, it is inevitable that these levels will converge in the future. This paper studies this future convergence, including the hypothesis that the southern and eastern shores will catch up with the northern shore. It also envisages a potential challenge to the spatial dichotomy of demographic ageing in the Mediterranean. To this end, we will go beyond the national frameworks generally used for studies of the Mediterranean as a whole and examine each Mediterranean country at a sub national level. After creating demographic projections based on 4 prospective scenarios, we will use various methods (cartography, spatial statistics, etc.) to express how the southern regions will catch up, how the space will change, and how the spatial dichotomy of ageing in the Mediterranean will evolve.
\end{abstract}

Keywords: Spatial Demography, Demographic Ageing, Mediterranean, Spatial Convergence, Spatial Autocorrelation, Local Indicators of Spatial Association (LISA).

Acknowledgments: I thank Isabelle Blöss-Widmer for her proofreadings and advise. This article was written as part of the SoDeMoMed project, funded by ANR Transmed (ANR-12-TMED-0005).

\section{Introduction}

In the early $21^{\text {st }}$ century, the Mediterranean is presented instead as a heterogeneous geographical area marked by contrasts. Demography has also contributed to the construction of the idea of the Mediterranean as an opposition between two areas, particularly with regards to fertility, 
population growth and the age structure of the population. Indeed, a northern shore in decline, with low fertility rates and an ageing population, as opposed to the young and fertile southern and eastern shores, which are experiencing rapid growth. However, this spatial dichotomy north-south arises from a cross-sectional view of the demographic situation of each Mediterranean population. This spatial dichotomy does not consider the dynamic nature of demographic phenomena in terms of time and space. However, the Mediterranean demography is in flux as demographic transition spreads. For example, fertility and growth rates disparities are thus declining in the Mediterranean. They are now considerably less marked than in the 1970 's. These two transformations reveal the extent to which there exists an overall trend for the reduction of demographic disparities in the Mediterranean (Courbage and Todd 2014). However, the north-south opposition is still present if we consider their age structures: the northern shore is elderly, while the southern and eastern shores are young. Demographic transition will automatically lead to an ageing of the populations in question, and this will occur over an even shorter period of time given that the transition is happening quickly. The populations of the southern and eastern shores will therefore age faster than those on the northern shore (Pison 2009).

We then can reassess the Mediterranean as not simply a region of contrasts, but a region undergoing homogenisation. This factor becomes significant when demography is used to consider international relations. The clash of civilisations (Huntington 1993), for example, conceptualises the youthfulness of Arab-Muslim societies (against the ageing societies of Europe) as a determining cause of a war between civilisations. In this context, the current demography is thought to be unchanging, consequently rendering political unrest and conflicts in the Mediterranean unchanging too. The lessening of demographic contrasts, and in particular the upcoming ageing of the southern and eastern shores, is a solid argument against the clash of civilisations and its bellicose predictions.

Today, we find ourselves in a paradoxical situation. While disparities in the level of ageing are destined to be reduced in the Mediterranean, there are very few prospective studies on the subject. The objective of this article is to fill this gap by conducting a prospective study of demographic ageing in the Mediterranean. Particular attention is paid to the future development of the North-South spatial dichotomy. Should we envisage a partial or a total convergence between regions on both sides of the Mediterranean? Will the regions of the southern and eastern shores catch up with those of the northern shore in terms of their respective levels of ageing? Will the spatial dichotomy of ageing in the Mediterranean continue? Or will it be reduced in the much the same way as population growth and fertility?

This article's contributions to literature on Mediterranean demography are significant. Firstly, very few studies deal with the issue of demographic ageing in the Mediterranean, and even fewer do a prospective study on this phenomenon. Furthermore, we consider the Mediterranean as a whole, that is to say both its southern and eastern shores and its northern shore, while the vast majority of literature relates to one or several countries in this geographical area. Then we made the methodological choice to use a sub-national level of analysis, which is very rare in 
Mediterranean studies. Finally, producing and analysing demographic projections for subnational regions on the northern, southern and eastern shores of the Mediterranean is truly original and offers a major contribution to the literature. Indeed, the methodological choices made in this article enable to study the Mediterranean in more detail than is usually done in the literature. Thus, our study reveals some original elements. We highlight that the dichotomy between the northern shore and the southern and eastern shores with regards to the level of ageing will partially disappear in the future. The results make it possible to geographically deconstruct the categories "north shore" and "south and east shore" by adding nuances to the demographic trends within these geographical areas. In particular, we show that other demographic divides in the Mediterranean than the north/south opposition, in particular internal divides on each shore. Not all regions on the southern and eastern shores age at the same intensity. Some regions will certainly show a similar level of ageing to those on the northern shore, while others will remain among the youngest in the Mediterranean. Similarly, the results show a differentiated demographic ageing in the territories of the northern shore, where some will have a marked ageing and others a moderate ageing, close to that of territories on the southern and eastern shores.

The article is structured in 5 sections. First of all, we will take stock of the various demographic transitions currently underway in Mediterranean countries. This section makes it possible to grasp the inevitable and mechanical nature of the future convergence of demographic ageing in the Mediterranean. Then, we will carry out a literature review and present our research questions. Thirdly, we will present the data, the construction of potential scenarios and the methods used. The results will form the fourth section. These will highlight a partial convergence of demographic ageing, resulting in an overall reduction of disparities, territorial convergences and a lessening of the spatial dichotomy in the Mediterranean. The final section of this article will bring together the discussion of the results and the conclusion.

\section{Demographic transitions: the converging Mediterranean}

The demographic transition is generally defined as the transition from a demographic stage characterised by high mortality/fertility (thus a "high" near-equilibrium ${ }^{1}$ ) to a demographic stage characterised by low mortality/fertility (thus a "low" near-equilibrium) (Chesnais 2011). Using UN data ${ }^{2}$ relating to Mediterranean countries ${ }^{3}$ over the period 1950-2015, we will first study the changes in general mortality (expectation of life at birth) before focusing on changes in fertility rates. Demographic ageing is a direct consequence of demographic transition: the decline in mortality leads to "ageing from the top" of the age pyramid, and the decline in fertility to "ageing from the bottom" of the age pyramid ${ }^{4}$. Taking stock of the demographic transitions underway in the Mediterranean therefore comes down to analysing the underlying processes in order to better understand future developments. Finally, we will highlight the link between the demographic changes associated with the demographic transition and the future convergence of demographic ageing in the Mediterranean. 


\subsection{A widespread fall in fertility and mortality rates}

\subsubsection{Overall convergence of mortality rates}

Between 1950 and 2015, we witnessed a widespread convergence of mortality rates among Mediterranean countries (see Fig 1). In 1950, there was an undeniable dichotomy with respect to the expectation of life at birth ${ }^{5}$. The first group of countries consisted of those on the northern shore, with the addition of Israel and Cyprus. Most of these countries had an expectation of life at birth of over 59 years $^{6}$. The second group consisted of the southern and eastern Mediterranean countries, which had an expectation of life at birth of less than 50 years. Between 1950 and 2015, the expectation of life at birth of these two groups very quickly converged, reaching around 70 years. The southern and eastern Mediterranean countries therefore largely closed the gap and caught up with the countries of the northern shore. This process of convergence greatly reduced the mortality rate disparities between countries. The way in which the southern and eastern Mediterranean countries have caught up since 1950 can be explained by the fact that their mortality transition, despite occurring later than elsewhere, also took place very rapidly. The factors responsible for the decline in mortality are related to the progress of medicine and technology, socio-economic development, an increase in the educational level of the population and improvements in nutrition, etc. The very rapid decline in mortality in southern and eastern Mediterranean countries largely reflects the decline in infectious diseases. By 1950, the means of fighting most of these diseases were already in existence. The technologies used are unsophisticated and inexpensive, limiting the impact of level of wealth in acquiring them. This allowed poor countries to achieve a life expectancy at birth close to that of wealthy countries in the 1970s-1980s, without major economic development (Preston 1975).

This rapid shift in life expectancy at birth from under 50 to 70 years of age, which took place over a period of less than 30 years in some cases, is the result of profound upheavals affecting morbidity patterns and the causes and timing of mortality. Across the Mediterranean as a whole, North African countries had the lowest life expectancy at birth in 1950 (<46 years), but they also demonstrated the fastest growth in this area. These countries gained between 28 years (Morocco) and 35 years (Libya) in terms of life expectancy between 1950 and 2015. Overall, there have been no major upheavals in the hierarchy of countries: those which had the highest expectation of life at birth in 1950 generally still do in 2015. If we examine the data in detail, however, we see that there are singular shifts by means of which some southern and eastern Mediterranean countries are clearly catching up with or even overtaking certain northern countries. The countries in question are Lebanon, Tunisia, Syria and Turkey, which boasted a higher expectation of life at birth than Serbia and Bulgaria in 2015. Lebanon has even moved ahead of many of the Balkan countries (Albania, Croatia, Bosnia and Herzegovina, Montenegro, Macedonia, Serbia, Bulgaria).

However, this overall convergence of mortality rates gradually slowed (and even stopped) in the 1990's. Life expectancy at birth is a broad indicator that can mask contrasting mortality patterns and health circumstances. The slowdown in the overall convergence of mortality rates 
in the Mediterranean can be explained by the differentiation in the convergence of mortality rates depending on age. Over time, the process by which mortality rates fall is not distributed evenly across all age ranges. The rate initially falls among young people, then adults, before finally spreading to the elderly (Reher 2004). In 1950, there was a great deal of variation in the mortality rates of these three age groups among the countries of the Mediterranean. Between 1950 and 2015, infant/child and adult mortality rates became highly homogenised, leading to a reduction in the overall mortality rate of the Mediterranean. The rate of this reduction dropped over time as the gaps in infant/child and adult mortality rates were generally bridged. In fact, the fall in general mortality rates can only continue now if there is a reduction in the mortality rate among the elderly. However, the latter is currently demonstrating a divergent tendency. Life expectancy at age 65 has risen faster in the northern countries, accentuating the discrepancies between the countries of the Mediterranean. This explains the slowdown in the convergence of general mortality rates since the 2000's after a pronounced pattern of convergence from 1950 onward. 


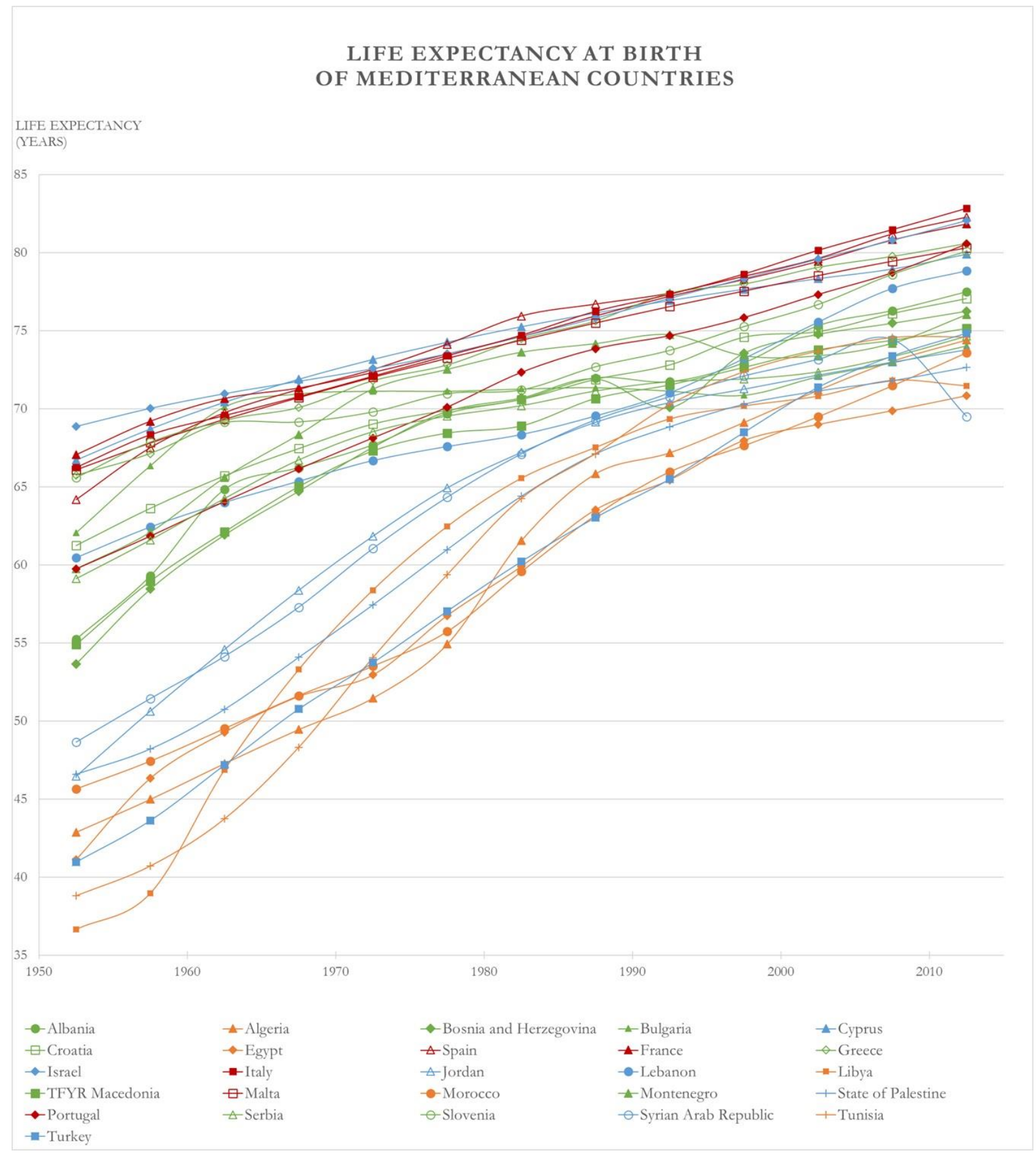

Fig 1: Life expectancy at birth in Mediterranean countries (1950-2015)

\subsubsection{Are fertility rates converging towards differentiated levels?}

In order to understand fertility levels, we will use the Total Fertility Rate (TFR), whose unit is expressed in number of children per woman. In 1950, there was a major disparity in fertility levels across the Mediterranean region; this was reflective of the fact that the various countries were at different stages of the demographic transition (see Fig 2). Several countries were in the final stages of the fertility transition, with a TFR of between 2 and 3 children per woman. These countries were France, Spain, Bulgaria, Croatia, Greece, Slovenia, Italy and Portugal. Some were in the transitional phase, with a TFR of between 3 and 5 children per woman: Cyprus, Montenegro, Bosnia and Herzegovina, Serbia, Malta, Israel. Other countries had not yet begun the fertility transition; their TFR remained at pre-transitional levels, i.e. between 6 and 8 children per woman. This was the case in Lebanon, Turkey, Albania, 
Macedonia, Libya, Morocco, Tunisia, Algeria, Egypt, Jordan, Palestine and Syria. In the period from 1950-2015, a majority of developing countries saw their fertility rates converge towards lower levels (Wilson 2001, 2011). The southern and eastern Mediterranean countries also saw their fertility rates decrease very quickly from the 1970 's/80's onward. The factors responsible for the decline in fertility have been the subject of intense debate among demographers. Originally, the theoretical framework of modernisation highlighted economic progress as an explanation for this process. Subsequently, research has extended the explanatory factors to include education, literacy, urbanisation, basic fertility determinants, delaying the age of marriage, and so on.

In 1950, fertility rates were distributed along a scale in which the highest rate was three times the lowest. In the period from 1980-1990, i.e. the time when fertility began to decline in the majority of southern and eastern Mediterranean countries, the highest fertility rate was five times the lowest! These gaps then began to gradually shrink until 2015. On the whole, the fertility gaps between Mediterranean countries narrowed between 1950 and 2015. Fertility rates in Mediterranean countries converged to an extent, all falling to lower levels. As of 2015, however, they have not converged completely: there are still some disparities. While many countries on the northern shore have a fertility rate of less than 2 children per woman, the fertility rate of some countries on the southern and eastern shores remains above 3, e.g. Algeria, Egypt, Jordan, Palestine and Syria. Nevertheless, fertility in certain southern countries may stabilise at slightly higher levels than in the northern countries. Morocco, for example, has a fertility rate of 2.2 children per woman, and this has remained largely stable since the mid2000 's. This new equilibrium may hint at the end of the fertility transition, or possibly at a plateau before another fall (or rise) in fertility rates, as happened in Egypt in the 1970's (Ambrosetti 2011).

In this article, we chose not to dwell on this recent rise in fertility, called "counter-transition" by some (Courbage 2015a). The countries concerned are Algeria, Morocco, Tunisia and Egypt (Al Zalak and Goujon 2017; Ambrosetti 2014; Courbage 2015b; Ouadah-Bedidi et al. 2012). Experts have not yet reached a consensus on this issue. It could be due to a cyclical effect linked to the Arab revolutions, a potential return to traditional values, or several other factors. In the case of Algeria, one could imagine a post-Civil War effect like the baby boom that followed the Second World War, since this rise in fertility has been ongoing for more than 15 years now. Nevertheless, it is unlikely that these rising fertility trends will cancel out the sociocultural changes linked to the demographic transition (Courbage 2015b). 


\section{TOTAL FERTILITY RATE \\ OF MEDITERRANEAN COUNTRIES}

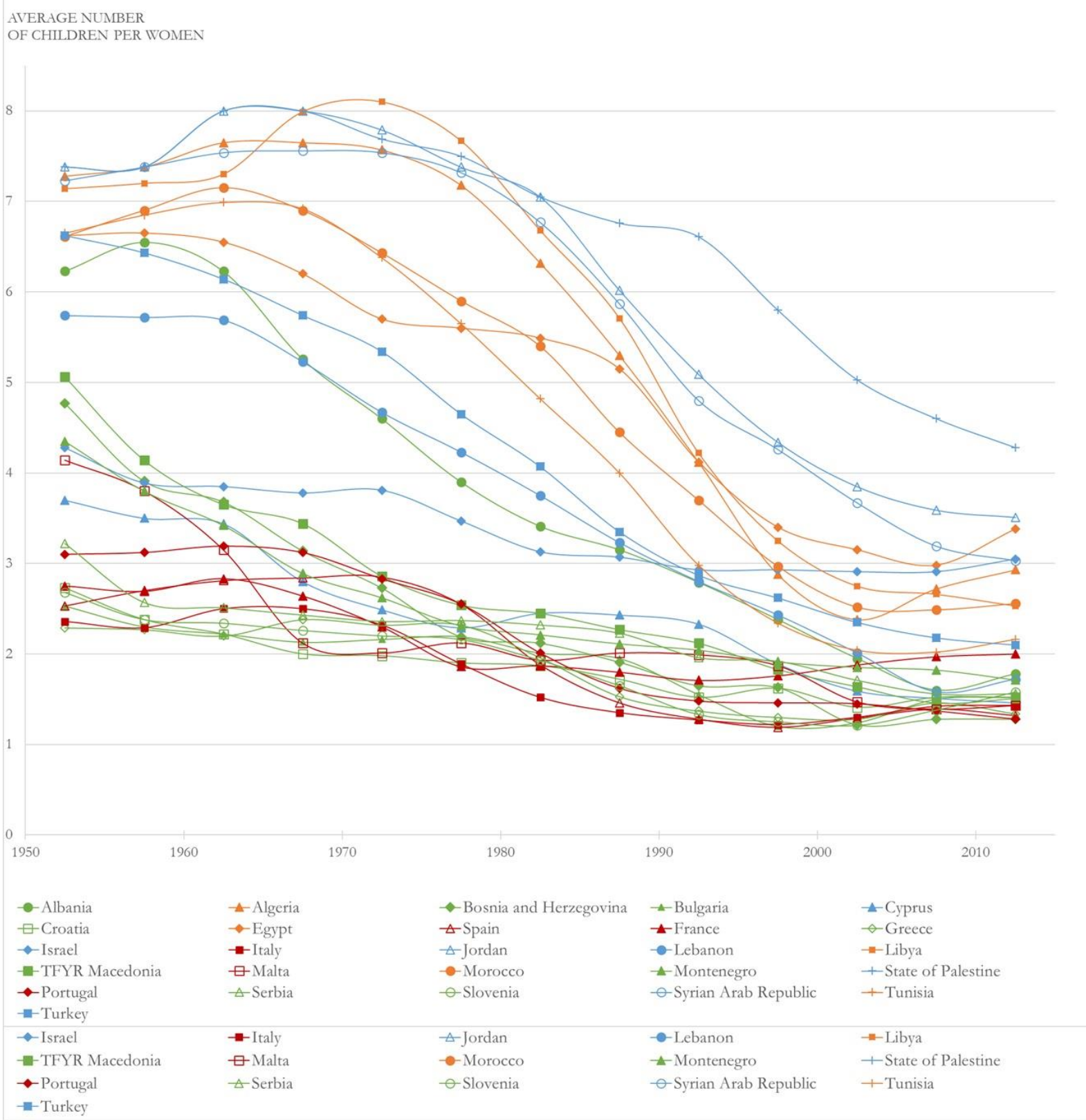

Fig 2: Total Fertility Rate of Mediterranean countries (1950-2015)

\subsection{The inevitable convergence of demographic ageing}

Since 1950, the demographic transition of the Mediterranean countries has led to the convergence of mortality and fertility rates at low levels, resulting in an overall reduction in the disparities between countries. This process of convergence, an intrinsic aspect of the demographic transition, inevitably results in the ageing of the population pyramid as it passes through several stages (Chesnais 1992). As the mortality rate falls, the population pyramid initially skews towards youth, as the increased chance of survival benefits young people at first. The fall in mortality only begins to produce an ageing effect when it starts to benefit adults and 
the elderly. When this occurs, more and more people start to live to an advanced age, increasing the weight of the upper levels of the population pyramid. The ageing effect caused by mortality rates is called "ageing from the top". The decline in fertility, the second stage of the demographic transition, shrinks the base of the population pyramid. This decreases the proportion of the total population made up of the youngest members of society, automatically increasing the proportion of elderly people. The ageing effect caused by declining fertility is called "ageing from the bottom" of the population pyramid. When the demographic transition is complete, i.e. when birth and mortality rates have stabilised, the effects of ageing from the bottom are sharply reduced. At this stage, demographic ageing mainly occurs from the top of the population pyramid due to the arrival in old age of several generations from the transitional stage born before the decline in fertility rates. In the last phase, the level of ageing becomes stable as fertility and mortality rates stabilise (provided these two phenomena reach equilibrium in the post-transitional stage).

These theoretical mechanisms show how demographic ageing is a direct and automatic consequence of the demographic transition. The convergence of birth and mortality rates at low levels automatically results in the transformation of the population pyramid from young to older, i.e. from a low level of ageing to a high level.

Since all Mediterranean countries are undergoing the demographic transition, we might expect their levels of ageing to converge. However, between 1950 and 2015, we can see that the opposite trend occurred: levels of ageing across the Mediterranean diverged. The countries of the northern shore aged faster than the southern and eastern countries, thus increasing the disparities between them in terms of ageing. This divergence can be explained by the inertia of demographic phenomena. A certain amount of time passes between the beginning of the transition and the onset of demographic ageing. This period of time can vary depending on the transition, since the form of the demographic transition conditions the speed and intensity of the ageing process. Developed countries that transitioned early therefore experienced a slower ageing process than those that transitioned later (Pison 2008). This is mainly due to how quickly fertility rates fall: slowly in developed countries, and quickly (sometimes very quickly) in countries transitioning late. France, for example, had to wait almost 115 years for the proportion of its population aged over 65 to rise from $7 \%$ to $14 \%$; the same shift took only 20 years in Bosnia and Herzegovina (Pison 2009). With a faster demographic transition, the young countries of the southern and eastern shores will age faster than the northern countries. According to various projections, they will undergo a convergent shift that reduces the gap separating them from the older countries. 


\section{Background and research questions}

For the literature review, we have chosen to present 3 characteristics of the demographic literature concerning the Mediterranean. This highlights the gaps that our article seeks to fill.

The first concerns the scale used by Mediterranean studies: national, regional or pan-Mediterranean. The national scale remains the most common, with many monographs having been published on a particular Mediterranean country. Regional studies, on the other hand, deal with a specific region of the Mediterranean. The regions concerned are, for example, the Maghreb (Fargues 1990, Ouadah-Bedidi et al 2012, Sebti et al. 2009), the Near East (Courbage 2008, Fargues 1995, 2006), the southern and eastern shores of the Mediterranean (Courbage 1997, 1999, 2011, Fargues 2000a), the Balkans (Deslondes 2004, Parant and Penev 2009, Sardon 2004), or the countries of Southern Europe (Avdeev et al 2011, Doignon et al 2016, Pfirsch 2011). But ultimately, demographic studies covering the entire Mediterranean region (pan-Mediterranean) are scarce (Attané and Courbage 2001, Carella and Parant 2016, D'Addato 2010, Fargues 2000b, Fargues and Salinari 2011, ITAN 2014a, 2015, Oliveau and Doignon 2014, Troisi and Von Kondratowitz 2013, Wilson 2005, Zagaglia 2013). This situation is paradoxical since this is a region of the world which has been heavily studied by population sciences. This assessment contrasts with other social sciences where there has been significant reflection on the homogeneity of Mediterranean societies. In particular, this has lead to an approach which considers the Mediterranean as a whole, as a logical geographic area. Notably, we consider the literature of anthropology (Albera 2006, Blok et al 2001, Bromberger and Durand 2001, Herzfeld 1987, Peristiany 1963, 1966, 1976, Pina-Cabral 1989, Tolosana 2001), in geography (Béthemont 2001, Brunet 1995, Deprest 2002, Dollfus 1995), or in history (Bourguet et al 1998, Braudel 1949, 1977, Chastagnaret and Ilbert 1991, Ilbert 1992, Roncayolo 2002).

The second characteristic of demographic literature on the Mediterranean is related to the issues addressed. Principally, this includes population growth, fertility, international migration, the significant share of young people in the population, or the demographic window and its impact on labour markets. It is clear that population ageing is not one of the issues addressed for the whole of the Mediterranean. However, contemporary developments linked to demographic transitions in the Mediterranean note an inevitable convergence of the demographic ageing of the north shore and the southern and eastern shores in the coming decades. The United Nations has identified this phenomenon as unprecedented, universal, enduring, irreversible and far-reaching, constituting the major demographic disruption of the 21 st century (United Nations 2002). In this context, a prospective study on demographic ageing is necessary in order to anticipate the consequences. To our knowledge, only the study conducted by J. Troisi and H.-J. Kondratowitz (2013) explicitly addresses this issue in the context of the Mediterranean and creates a prospective study of it. These authors have already noted the lack of studies on the subject as the Mediterranean region has been scarcely studied as a separate entity.

Finally, the last characteristic of the literature concerns the level of observation employed. This is, in the vast majority of studies dealing with the Mediterranean as a whole, at a national level. This analysis therefore focusses on all Mediterranean countries. However, the population sciences have shown that this level of observation is not adapted to the study of demographic phenomena. It obscures important processes such as internal migration, urbanrural contrasts, specific territorial dynamics, internal cultural differences or depopulation. The national level thus presents the enormous disadvantage of masking great demographic disparities within an individual country. For example, the north-south demographic oppositions in Italy, east-west in Turkey, or littoral-hinterland contrasts of the countries of the Near East. Despite these disadvantages at the national level, there are very few studies which adopt a subnational level of analysis to study the Mediterranean as a whole. To our knowledge, only two studies have done this (Attané and Courbage 2001, ITAN 2014a, 2015). The report by Y. Courbage and I. Attané (2001) analyses subnational regions (NUTS 3 equivalent) of all Mediterranean countries. Nevertheless, it focuses only on the coastal regions of the sea. Under this approach, a region 40 kilometres from the sea may not be considered as Mediterranean. This is a very restrictive and debatable definition of the Mediterranean. The second study is the ITAN project (Integrated Territorial Analysis of the Neighbourhood) funded by the European Union (ESPON programme). Several reports of this project (ITAN 2014b, 2014a, 2015) build a current inventory of the 
demography of the Mediterranean at a subnational level, but not a prospective study of the demographic dimension and population ageing.

To date, only a few prospective studies on the possible future of demographic ageing in the Mediterranean have been carried out, and even fewer have incorporated the concept of the southern and eastern shores catching up with the northern shore. Where these studies exist, they are often limited to the country level and do not take into account the process of convergence produced mechanically by the demographic transitions of the second half of the 20th century. To fill the gaps in the literature, we have studied demographic ageing in the Mediterranean, on a pan-Mediterranean scale and with a subnational level of observation.

This theme may lead to the study of many demographic aspects. For this article, we have chosen to limit ourselves to 3 research questions:

- Research question 1: Overall, will the regions of the southern and eastern shores catch up with those on the north shore? Should we imagine this to be a total or partial catch-up? We are seeking to find out if the Mediterranean regions would converge around the same level of ageing over the next 50 years.

We hypothesise that the southern and eastern shores will catch up. On the other hand, we predict a partial convergence, that is to say that not all of the regions of the southern and eastern shores will catch up with the north shore.

- Research question 2: In the case of partial convergence, which regions on the southern and eastern shores will reach the same levels of ageing as northern shore regions?

We postulate that the regions implicated in this catch-up are those most advanced in demographic transition.

- Research question 3: will the North-South spatial dichotomy of demographic ageing in the Mediterranean be re-assessed?

We hypothesise that this North-South opposition will be mitigated by the process of convergence, and that in the future it will be less obvious than at present.

\section{Methodological aspects of a sub national forecast of demographic ageing in the Mediterranean}

4.1. Sub national division and data

With a sub-national approach, it is therefore necessary to develop sub national divisions that allow for comparisons between several countries. For the purposes of this study, we have devised a sub national territorial grid covering the entire Mediterranean (made up of 778 territorial units). The criterion used to select the administrative level of each country is its surface area. The final grid is optimised to minimise size disparities between regions without modifying the existing administrative network.

To draw up these demographic projections, we collected data on fertility, mortality, age and sex structure for all the regions involved in the study. Unlike the European Union, which centralises the statistics pertaining to its various member countries by means of a dedicated agency (Eurostat), the Mediterranean countries do not have a centralised body. For this reason, we turned to the national statistics offices of each Mediterranean country to gather the data needed for our projections. However, not all national offices were able to provide all the necessary data. To make up for these shortcomings, we also collected data from Eurostat, the United Nations (World Population Prospects), specific national ministries, and international programmes (Demographic and Health Surveys (DHS); World Bank). A detailed list of the institutions that provided the data used in our work is presented in Fig 3. The data was collected in various ways: directly from the websites of the providers mentioned, via database queries, from annual publications such as Statistical Yearbooks, and from specific publications. 
With regard to our data sources, we used population censuses, population registers, or the latest estimates from the national statistics office of each country for our data on age and sex structures. In terms of fertility and mortality rates, the data is mainly taken from vital records and population registers, but some information comes from international or national surveys such as DHS surveys or national demographic surveys.

After gathering this information, we found ourselves faced with a heterogeneous data set that varied enormously from one country to the next; certain data was completely lacking. With regard to fertility, for example, some national statistics offices provide the TFR or age-specific fertility rates for each sub national region, while others only provide the number of births or the gross birth rate. However, we required age-specific fertility rates to create our demographic projections. To compensate for incomplete or unavailable data, we used indirect estimation methods (Moultrie et al. 2013). Once this process was complete, we were left with a homogeneous data set covering all Mediterranean regions. 


\begin{tabular}{|c|c|c|}
\hline & Signification & Website \\
\hline \multirow{4}{*}{$\begin{array}{l}\text { International } \\
\text { organisation }\end{array}$} & Demographic and Health Surveys & http://dhsprogram.com/ \\
\hline & United Nations & http://www.un.org/ \\
\hline & World Population Prospects & https://esa.un.org/unpd/wpp/ \\
\hline & Eurostat & http://ec.europa.eu/eurostat/fr/home \\
\hline Albania & Instituti I Statistikave & http://www.instat.gov.al/ \\
\hline Algeria & Office National des Statistiques & http://www.ons.dz/ \\
\hline \multirow{3}{*}{$\begin{array}{l}\text { Bosnia and } \\
\text { Herzegovina }\end{array}$} & Republika Srpska Institute of Statistics & http://www.rzs.rs.ba/ \\
\hline & Federal Office of Statistics & http://www.fzs.ba \\
\hline & Bosna i Hercegovina Agencija za Statistiku & http://www.bhas.ba/ \\
\hline Bulgaria & National Statistical Institute & http://www.nsi.bg/ \\
\hline Cyprus & Statistical Service of Cyprus & http://www.mof.gov.cy \\
\hline Croatia & Croatian Bureau of Statistics & http://www.dzs.hr/ \\
\hline Egypt & $\begin{array}{l}\text { Central Agency for Public Mobilization and } \\
\text { Statistics }\end{array}$ & http://www.capmas.gov.eg/ \\
\hline Spain & Instituto Nacional de Estadistica & http://www.ine.es/ \\
\hline France & $\begin{array}{c}\text { Institut National de la Statistique et des Études } \\
\text { Economiques }\end{array}$ & http://www.insee.fr/ \\
\hline Greece & Hellenic Statistical Authority & http://www.statistics.gr/ \\
\hline Israel & Central Bureau of Statistics & http://www.cbs.gov.il/ \\
\hline Italy & Istituto Nazionale di Statistica & http://www.istat.it/ \\
\hline \multirow[b]{2}{*}{ Jordan } & Department of Statistics & http://web.dos.gov.jo/ \\
\hline & Jordan Fertility and Family Health Survery & \\
\hline Kosovo & Agjencia e Statistikave Të Kosovës & http://ask.rks-gov.net/ \\
\hline \multirow{2}{*}{ Lebanon } & Ministry Of Public Health & http://www.moph.gov.lb/ \\
\hline & Central Administration of Statistics & http://www.cas.gov.lb/ \\
\hline Libya & Bureau of Statistics and Census Libya & http://www.bsc.ly/ \\
\hline TFYR Macedonia & State Statistical Office & http://www.stat.gov.mk/ \\
\hline Malta & National Statistics Office & https://nso.gov.mt/ \\
\hline Morocco & Haut-Commissariat au Plan & http://www.hcp.ma/ \\
\hline Montenegro & Statistical Office of Montenegro & http://www.monstat.org/ \\
\hline State of Palestine & Palestinian Central Bureau of Statistics & http://www.pcbs.gov.ps/ \\
\hline Portugal & Instituto Nacional de Estatistica & https://www.ine.pt/ \\
\hline Serbia & Statistical Office of the Republic of Serbia & http://webrzs.stat.gov.rs/ \\
\hline Slovenia & Statistical Office of the Republic of Slovenia & http://www.stat.si/ \\
\hline Syria & Central Bureau of Statistics & http://www.cbssyr.sy/ \\
\hline \multirow{2}{*}{ Tunisia } & Institut National de la Statistique & http://www.ins.tn/ \\
\hline & Ministère de la santé & http://www.santetunisie.rns.tn/ \\
\hline Turkey & Turkish Statistical Institute & http://www.turkstat.gov.tr/ \\
\hline
\end{tabular}

Fig 3: Data providers 


\subsection{Constructing the prospective scenarios}

We created demographic projections of sub national regions using the component method over a time horizon of 50 years (2015-2065). We chose to make our projections based on closed populations, i.e. without considering the phenomenon of migration. The first reason for this choice is the difficulty of forecasting migration over a 50-year period. Barring the occurrence of one-off events, fertility and mortality trends are not subject to sudden and erratic variations, and can in this case be forecast as part of the theoretical framework of the demographic transition. On the other hand, migration is a short-term and more uncertain phenomenon which is considerably more difficult to model and predict, especially on a sub national scale. We believe that it would not be logical to draw up a scenario forecasting migration throughout the sub national regions of the entire Mediterranean with a time horizon of 50 years. In addition, data on migration varies enormously from one country to the next. It can be detailed (e.g. Spain, thanks to its population censuses), somewhat cursory, or even non-existent in some countries. Ultimately, migration data in the Mediterranean is too disparate for us to include the phenomenon of migration in our projections.

Using our data set, we constructed 4 prospective scenarios. To do so, we used the prospective trends indicated by the United Nations (taken from World Population Prospects) for each Mediterranean country. These national trends were then applied to the values of each sub national region of the country in question. Regarding mortality, we used the median UN trend for each scenario. For the development of fertility rates, on the other hand, we devised a precise hypothesis for each country and chose the UN trajectory that most closely corresponded to it. The 4 prospective scenarios are as follows:

- In the first scenario - the median scenario- the fertility trend follows the UN's median trajectory. This scenario suggests that fertility rates will converge at lower levels, potentially even below the replacement rate.

- In the second scenario - the model transition scenario- we assume that fertility rates will converge at a slightly higher level, close to the replacement rate. This scenario demonstrates an example of a practically ideal theoretical demographic transition, since the country's TFR is between 1.7 and 2.3 at the end of the period.

- The third scenario - the decelerated transition scenario-imagines a very slow (decelerated) convergence towards the replacement threshold. For regions where the TFR had already reached the replacement threshold in 2015, we projected that it would stabilise at this level.

- The last scenario - the rising fertility scenario- extends the recent recovery in fertility rates observed in some Arab-Muslim countries ${ }^{7}$. The fertility rate of these countries increases in the first few years of the projection and then begins to decrease very slowly, although it remains fairly high. We opted for the UN's median trajectory for all other countries.

\subsection{Methodological process}

The results presented in this article are produced through a 3-step process, each of which examines a different issue raised by our research questions. Our results will be structured in 3 sections.

First, we analyse convergence in the Mediterranean from a broader perspective. To measure a region's level of ageing, we used the following indicator: "proportion of the population aged 65 or over (in \%)". We initially studied the evolution of the statistical distribution of this indicator 
for each scenario between 2015 and 2065. This will help us to discover if there will be an overall or partial convergence. Then, we then analysed how the dispersion of this indicator changed over time with three indicators: the coefficient of variation, the coefficient of variation weighted by population, and the RDMA (Relative Dispersion Measure of Ageing) ${ }^{8}$. We calculated these dispersion indicators for each prospective scenario. In this way, we can assess if there is overall homogenisation of the level of ageing of the Mediterranean regions.

Secondly, the objective is to see if the regions across all the Mediterranean shores share the same level of ageing. We will focus on the trajectories of each region between 2015 and 2065, using mapping to identify the regions on the southern and eastern shores which will have the same level of ageing in 2065 as north shore regions. First, we calculate the difference between the "proportion of the popular tion aged 65 or over" and the Mediterranean average. To this end, we normalised the variable "proportion of the population aged 65 or over (in \%)", i.e. we subtracted the Mediterranean average for a given year from the value for a certain region in the same year. This will provide us with a new indicator of ageing. A positive difference indicates that the region is older than the Mediterranean average, and vice versa for a negative difference. If the gap between the local value and the Mediterranean average remains constant, it means that the region is ageing at the same speed as the Mediterranean. If the gap increases, the region is ageing faster than the Mediterranean.

Then, we will use the quintiles of the new "difference in the "share of those 65 years or older" from the Mediterranean average" to distinguish 5 categories of ageing: very young, young, average, older, very old. The level of ageing is therefore defined according to the position of each region in relation to the Mediterranean average. For example, the "young" category includes regions that are younger than the Mediterranean average. Each region therefore belongs to a category in 2015 and a category in 2065. It is possible for a region to transition from any given category to any other.

Finally, we will represent the regions of each category on a single map, i.e. regions which will have the same ageing situation in 2065. To simplify this representation and avoid producing excessive models, we focus on the median scenario. We chose only three ageing situations for 2065 from the 5 possibilities: the young regions (younger than the Mediterranean average) (see Fig 7), the average regions (in line with the Mediterranean average) (see Fig 8), and the old regions (older than the Mediterranean average) (see Fig 9). These situations provide the best illustration of the regional convergence of ageing in the Mediterranean, although nuances can be applied depending on the prospective scenario 9 . On the maps, we distinguish the regions according to their trajectory between 2015 and 2065 :

- Ascending trajectories (in sense of ageing): the ageing category of the region is older in 2065 than in 2015. This is coloured red on the maps.

- Stable trajectories: the ageing category of the region is the same in 2065 as in 2015. This is coloured grey on the maps. 
- Descending trajectories (in the sense of rejuvenating younger ${ }^{10}$ ): the ageing category of the region is younger in 2065 than in 2015. This is coloured blue on the maps.

Finally, we will measure the effect of region trajectories between 2015 and 2065 on the NorthSouth spatial dichotomy in the Mediterranean. So far, we have studied the trajectories of the regions without taking into account their geographical environment. However, the same trajectory will have a different effect on the local spatial structure depending on the area surrounding the region in question. For example, a young region that is ageing rapidly and is surrounded by already-elderly regions will reduce local disparities and lead to spatial homogenisation. This is a case of spatial convergence, i.e. convergence between a region and its neighbours. Conversely, imagine a young region that is ageing strongly but is surrounded by young regions that are ageing more slowly. In this case, the gaps between the region in question and the surrounding areas will increase. This is a case of spatial divergence, i.e. divergence between a region and its neighbours. This is a process that creates (or accentuates) spatial heterogeneity. Based on the trajectory of each region, and of their respective neighbourhoods, we can observe both areas of spatial convergence and areas of spatial divergence. It is the arrangement of these different areas that alters (or not, as the case may be) the spatial structure of a phenomenon, in this case the spatial dichotomy of ageing in the Mediterranean.

Initially, using a local index (local $\sigma$-convergence), we measured local changes in the space brought about by regional trajectories, whether they were cases of spatial convergence or spatial divergence. Calculating the local $\sigma$-convergence consists in working out the change in a dispersion indicator between two dates for each region and its neighbourhood (Bourdin 2013). In our case, we chose the coefficient of variation as a dispersion indicator. An index which is negative indicates local $\sigma$-convergence. In this case, spatial homogenisation takes place, since the gap between the region and its neighbourhood is reduced. Conversely, an index which is positive indicates local $\sigma$-divergence. In other words, the heterogeneity of the space is accentuated by an increase in the disparities between the individual region and its neighbourhood. The local $\sigma$-convergence is therefore a local change index which explicitly takes into account the spatial dimension of the data. Here, we measured the local $\sigma$-convergence of our ageing indicator (difference between the "proportion of the population aged 65 or over" and the Mediterranean average). The local convergence index therefore measures the change in the coefficient of variation of the ageing indicator for a region and its neighbours between 2015 and $2065^{11}$. We are only presenting the map of the local convergence indices for the median scenario here (see Fig 10), as the results for the other scenarios are largely similar.

We then analyse if the spatial structure of demographic ageing in the Mediterranean (opposition north-south) change between 2015 and 2065. To do this, we use local and global spatial autocorrelation index. These measure the structuring of a phenomenon in space and all the more so if this spatial structure changes over time. For the global spatial autocorrelation, we use Moran's I which varies between -1 and +1 . Moran's I provides information on the overall trend of all regions. However, like any global measurement, this index does not allow us to identify 
the presence of local spatial autocorrelation phenomena. Other indices have been developed to overcome this shortcoming presented by global measurements: these are the Local Indicators of Spatial Association (LISA) (Anselin 1995). They allow for the local decomposition of Moran's I. They measure the level of similarity between each region and its neighbourhood. The values of the LISA are grouped into 5 categories. Firstly, regions with high values whose neighbourhood also has high values. This group is represented in red. Next, regions with low values and a neighbourhood whose values are also low, represented in dark blue. Then come the cases of negative spatial autocorrelation: a region with a low value and a neighbourhood with high values (represented in light blue), or a region with a high value and a neighbourhood with low values (represented in light red). The final category includes regions whose value is not significantly different from the average; these are represented in white. This categorisation can be mapped in order to identify significant groupings of strong and weak values (i.e. the spatial structure of the phenomenon studied), thus allowing us to observe the change of a spatial structure over time.

\section{Results}

\subsection{Complete convergence or partial catch-up?}

\subsubsection{The southern and eastern shores will not completely catch up with the northern shore...}

In 2015, the distribution of the proportion of the population aged 65 and over in the Mediterranean was clearly bimodal, reflecting the dichotomy between the young regions and the older regions (see Fig 4). The first mode (mode no. 1) identifies the younger regions (level of ageing of around 5.5\%). The second mode (mode no. 2), meanwhile, concerns the older regions (level of ageing of around 21\%). The former are mainly regions on the southern and eastern shores, while the latter are regions on the northern shore. This finding can be partly explained by the extent to which the demographic transition has progressed: until now, the vast majority of populations in the southern and eastern Mediterranean have not started to age, or have aged very slowly.

\section{Distribution of the proportion of 65 years or over (2015)}

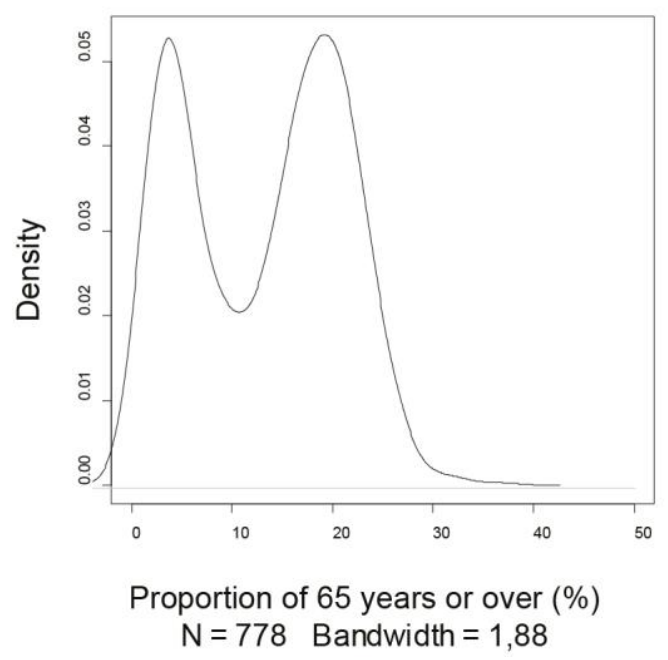

Fig 4: Distribution of the proportion of the population aged 65 or over (in \%) in 2015 
Fig 5 illustrates how this initial distribution has evolved in 2045 and 2065 according to the 4 prospective scenarios. Analysing these distributions highlights three key features. First, irrespective of the scenario, the entire Mediterranean will age over this period. The regions are generally older in 2065 than in 2015: we can see a general shift of all the curves to the right, indicating a rise in the proportion of the population aged 65 or over.

Moreover, the two modes are coming together and the gap between them is narrowing, signifying greater uniformity between the Mediterranean's two shores in terms of levels of ageing. The dichotomy between the two shores persists until 2045: the distribution remains bimodal in all the scenarios. In 2045, a third mode (mode no. 3) appears with higher values than mode no. 2. This reflects the rise of a new group of regions characterised by very pronounced ageing. In 2065, this third mode is not particularly visible in the model transition scenario, and to a lesser extent in the median scenario, but it is clearly identifiable in the decelerated transition and rising fertility scenarios.

Looking beyond these three shared characteristics (general ageing, standardisation of the proportion of the population aged 65 and over, and the emergence of very old regions), the most distant projection (2065) shows the most marked contrast between the scenarios. It seems that two potential situations may take shape. The first would see the north and south converge at a similar level of ageing, as illustrated by the Gaussian form of the 2065 curves for the median and model scenarios. By contrast, the other development would see ageing levels become stratified into 3 poles (the trimodal curve seen in the decelerated transition and rising fertility scenarios). 
Distribution of the proportion of 65 years or over (\%)

(2015-2065)

Median scenario

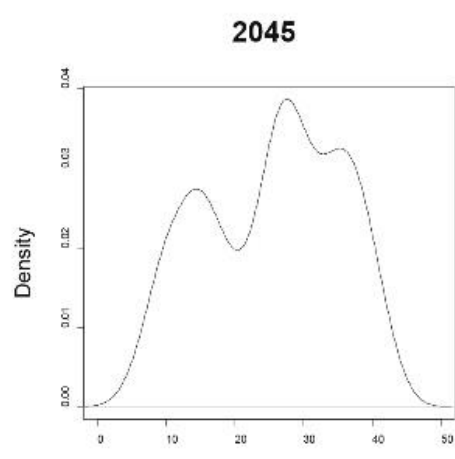

Proportion of the 65 years or over $(\%$ dwidth $=2363$

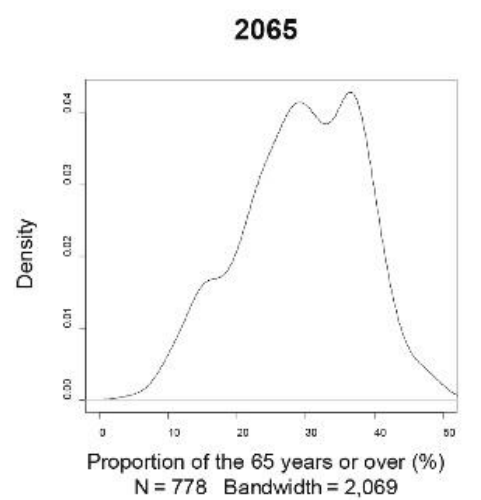

Ideal transition scenario

2045

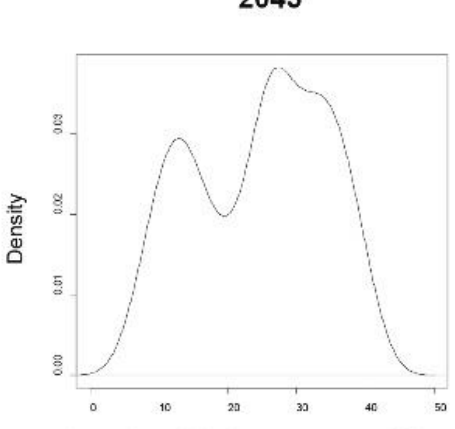

Proportion of the 65 years or over (

$N=778$ Bandwidth $=2316$

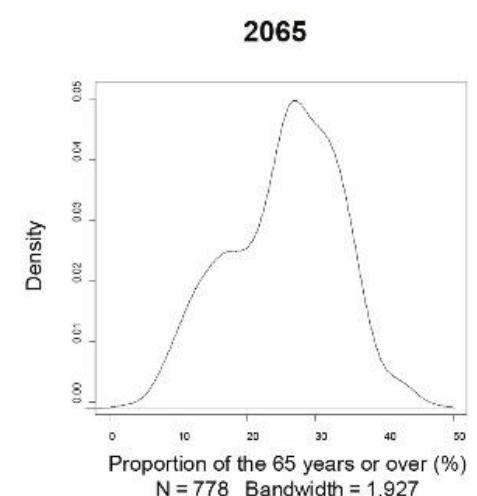

Slow transition scenario

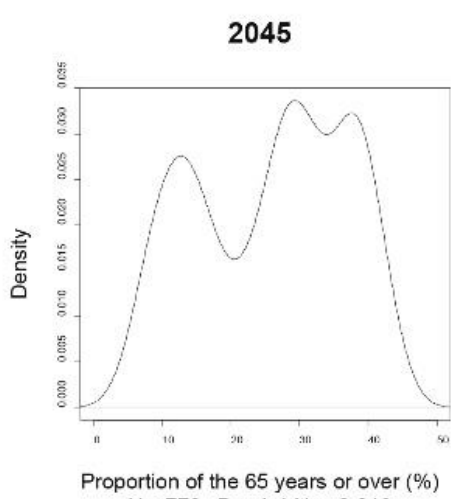

$\mathrm{N}=778$ the 65 years or over

2065

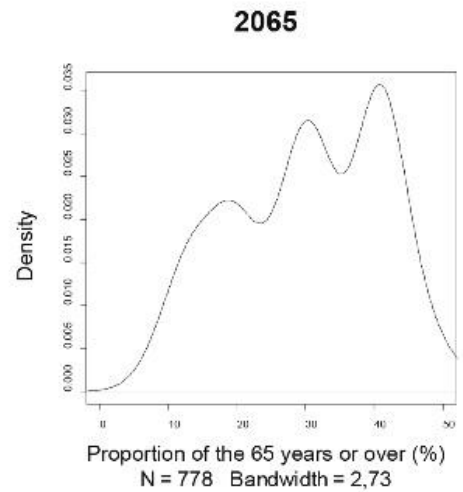

Fertility increase scenario

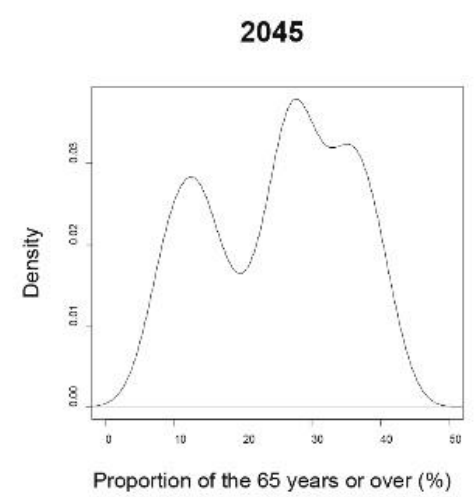

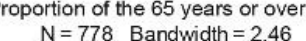

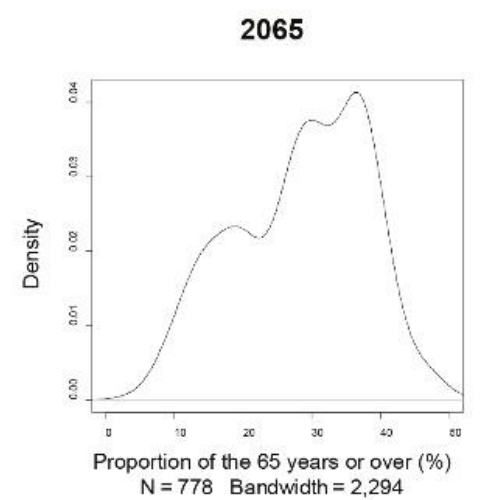

Author: Yoann Doignon (2019)

Fig 5: Distribution of the proportion of the population aged 65 or over (in \%) for the 4 scenarios in 2045 and 2065 
All the scenarios show the southern and eastern shores eventually beginning to catch up with the northern shore. However, they do not converge completely, since the distributions have not merged into a clearly Gaussian distribution in the 2065 projections. Nevertheless, this process of total convergence is almost complete in the median and model transition scenarios, i.e. in the cases where the fertility of all Mediterranean populations converges to a single, undifferentiated level. The projection of ageing at three differentiated levels, on the other hand, appears to be characteristic of the decelerated transition and rising fertility scenarios. In these situations, complete convergence does not take place. This can largely be explained by the hypotheses underpinning these two scenarios, which assume greater fertility gaps between regions than the other scenarios. It is manifest that a time horizon of 50 years, even assuming a rapid convergence of the fertility rates of all Mediterranean populations (median scenario and model transition scenario), will not be long enough for the complete convergence of demographic ageing to take place.

The fact that the southern and eastern shores do not completely catch up with the northern shore, however, does not invalidate the process of convergence itself. Indeed, it should be noted that we see the proportion of the population aged 65 or over converge across all Mediterranean regions. This implies that the youngest regions do indeed become older; however, they only partially bridge the gap. To objectify this aspect of our study and round out our observation of generalised but incomplete convergence, we decided to examine how the dispersion of the percentage of the population aged 65 or above changed over time. This could give a new and more dynamic meaning to the notion of convergence: greater proximity between ageing profiles across the Mediterranean in the future than at present.

\subsection{2. ... but the disparities between the two shores will be reduced}

All dispersion indicators reveal that dispersion will decrease between 2015 and 2065 (see Fig 6). The regions of the Mediterranean will therefore be less distant from each other in 2065 than in 2015. The reductions vary in magnitude across the different scenarios. For example, the decrease in dispersion is less pronounced in the decelerated transition scenario than in the other scenarios. This scenario is the one in which ageing levels converge most slowly. 


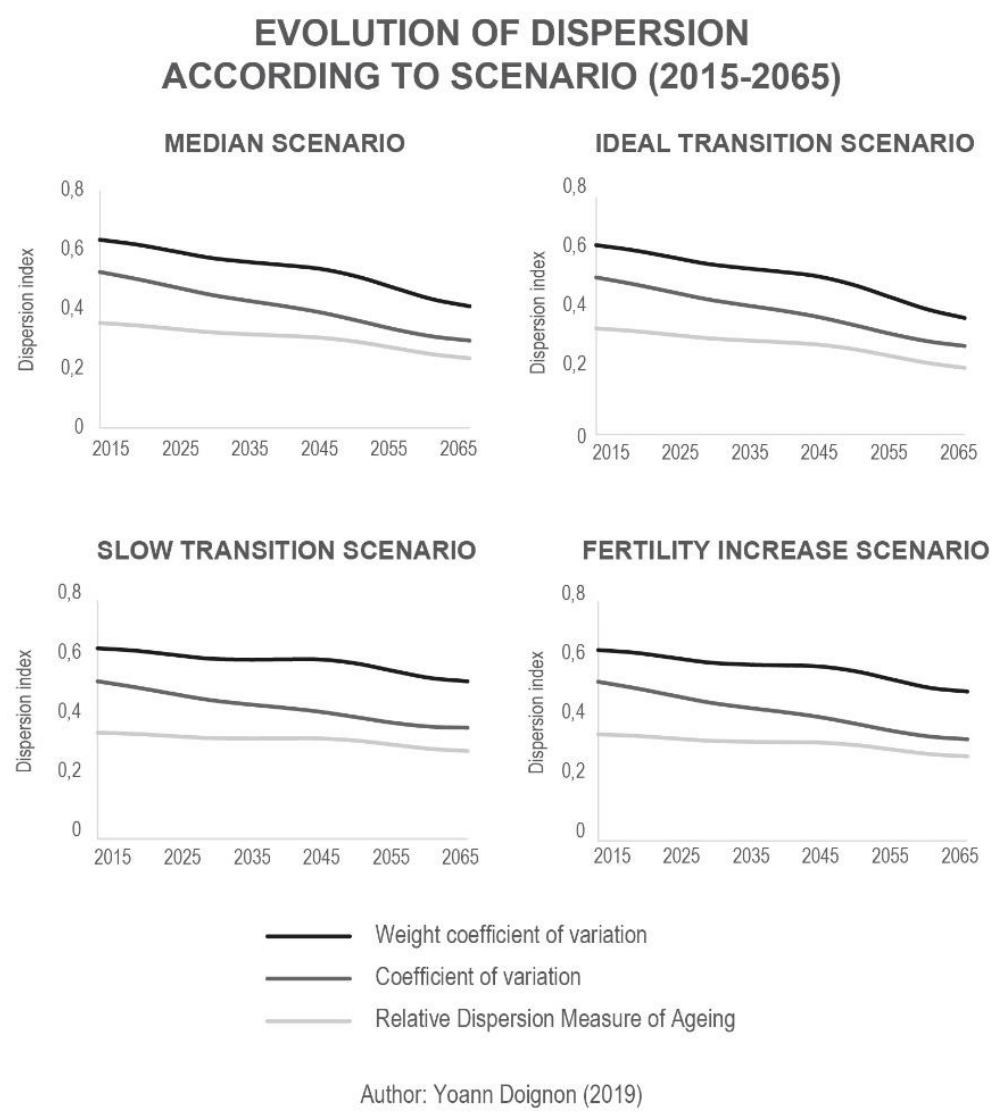

Fig 6: Evolution of the dispersion of the proportion of the population aged 65 or over by scenario

\subsection{Regional convergence: how the south will catch up with the north}

We will now look at the mapping of regional trajectories. Fig 7 shows that the "young" category is shared by many regions on the southern and eastern shores, but also by some northern regions. In 2065, these regions on both shores (represented in grey) will have a similar level of ageing, thus validating our theory that regions on the southern and eastern shores will catch up with the regions of the northern shore. This regional convergence is caused by two concomitant phenomena: the accelerated ageing of some regions of the southern and eastern shores, and the slower ageing of some northern regions. 


\section{TERRITORIES IN YOUNG CATEGORY IN 2065}

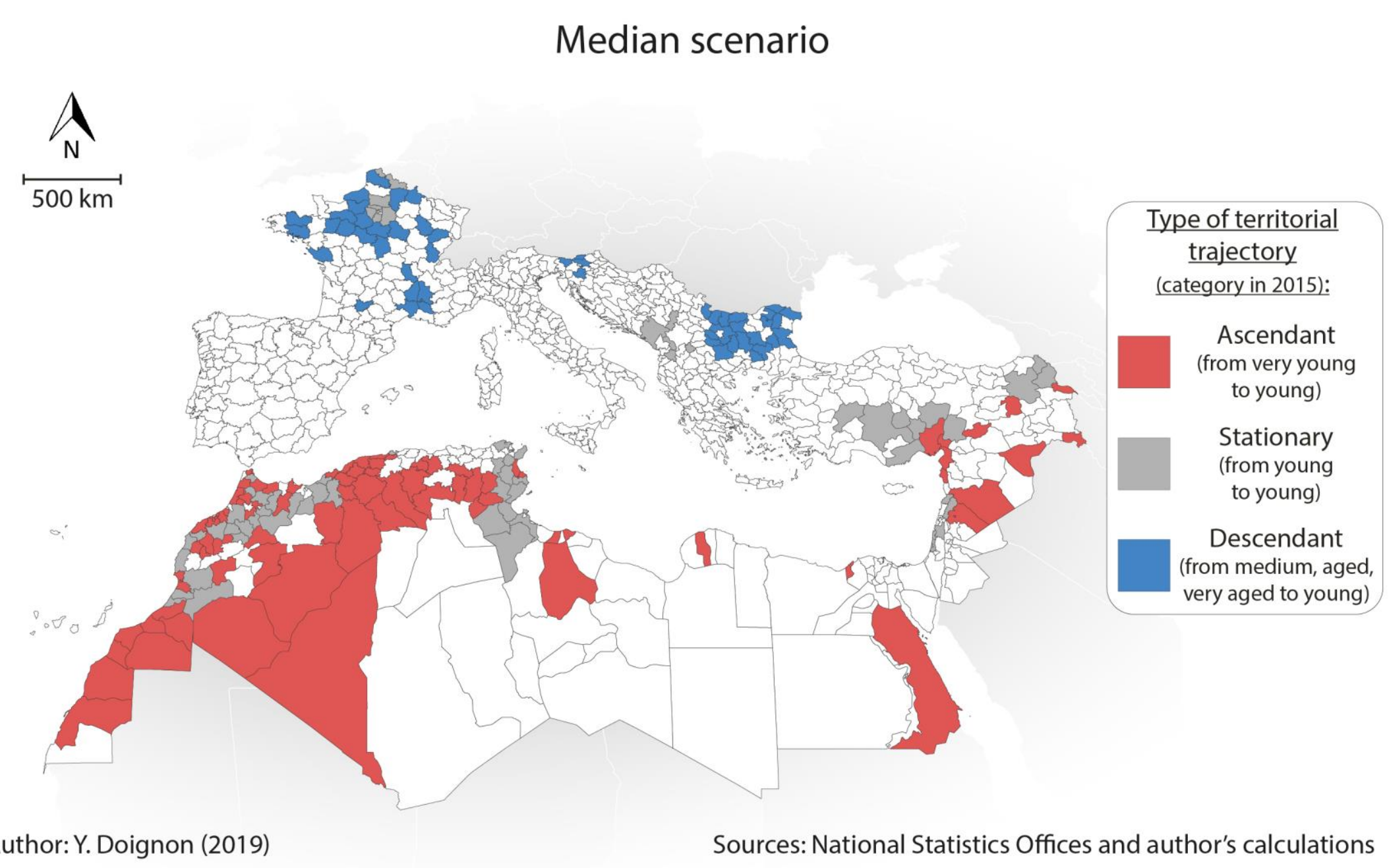

Fig 7: Regions in the "young" category in 2065 according to the median scenario 
The regions that are "very young" in 2015 and then go on to age faster than the Mediterranean average to reach the "young" category by 2065 make up the upward (ageing) trajectories (in red on the map). They are located in the west of the Maghreb region, especially on the Atlantic coast of Morocco, in Syria and in Turkey. The regions in question range from metropolises ${ }^{12}$ to deserts. On the one hand, these regions on the southern and eastern shores will catch up with "young" regions on the northern shore such as Skopje (Macedonia), Kosovo, Montenegro, the greater Paris area, a large part of Bulgaria, or the Albanian towns of Kukës and Dibër. On the other hand, they will gain ground on the oldest regions in the south and east in 2015 (not including Turkey), namely a large part of Tunisia and northern Morocco, Israel, etc.

However, Fig 7 also reveals a completely unexpected aspect of the convergence of demographic ageing in the Mediterranean: the fact that certain regions on the northern shore (in blue on the map) will become younger. Relatively speaking, these regions will get younger with regard to the average Mediterranean rate of ageing. This is an unprecedented situation, as we had not envisaged that northern regions could reverse the trend and begin to align with other younger regions. We find this type of trajectory in the north of France and in many of the Bulgarian regions. In both cases, full generations are replaced by empty generations in the 2050's/2060's, thus reducing the weight of the upper part of the population pyramid. For France, this mechanical phenomenon can be explained by the passing of the last members of the baby boom generation. For Bulgaria, it is caused by the passing of many generations born before the sudden decline in fertility in the late 1980 's. These irregular marks on the population pyramids produce an irregular rate of ageing.

The "average" category, which includes regions that have a level of ageing in line with the Mediterranean average, can be found on both shores of the Mediterranean (shown in grey in Fig 8). The ascending trajectories (ageing faster than the Mediterranean average) are mainly found on the coasts of the southern and eastern shores: in the centre and on part of the Mediterranean coast of Turkey, in Syria (Sweida, Tartus, sometimes Latakia), and in urban regions of the Maghreb (Jafara, Ben Arous, Ariana, Casablanca, Skikda, etc.). They are also found on the northern shore (northern Albania and Macedonia). The descending trajectories (ageing slower than the Mediterranean average or getting younger) are only found in regions on the northern shore: a large part of France, including the "empty diagonal", Bulgaria and Serbia. These ageing trajectories are the result of a combination of factors, explained in the first part of this chapter. Among all these factors (declining fertility and mortality rates, attractiveness of older populations, heliocentrism), it is worth emphasising that this map can identify spaces that could better control demographic ageing if they were able to limit emigration by their working-age population. The regions which remain stable (represented in grey, rate of ageing in line with the Mediterranean average) are mainly located in France and in the northern Balkans (Bosnia and Herzegovina, Croatia, Serbia, Slovenia). 


\section{TERRITORIES IN MEDIUM CATEGORY IN 2065}

\section{Median scenario}



Fig 8: Regions in the "average" category in 2065 according to the median scenario 
In the last map, the regions in the "old" category (older than the Mediterranean average, shown in grey) are mainly located on the northern shore in Spain, Italy, Greece and the Balkans (see Fig 9). However, some regions on the southern and eastern shores are also included (in Turkey and North Africa). This indicates that an elderly population pyramid will not necessarily remain the preserve of the northern regions, but may also affect regions in the south. The vast majority of the trajectories shown on this map are ascending. These regions are often close to each other geographically, as can be seen in the southern Iberian Peninsula, northern Italy, western Turkey, Greece, and Bosnia and Herzegovina.

This approach, broken down by regional trajectory, provides a contrast with the previous overall analysis, which showed that the southern and eastern shores will not completely catch up with the northern shore. The regional trajectories approach reveals that regions on both shores could belong to the same ageing categories in $2065^{13}$. Certain regions on the southern and eastern shores will completely overtake regions on the northern shore. Moreover, this analysis allows us to go beyond the framework according to which the regions of the southern and eastern shores will catch up with the northern regions. In reality, we have also revealed unexpected regional trajectories: some northern regions will begin to get younger, converging with regions on the southern and eastern shores. Here, we are not looking at a simple case of the southern and eastern shores "catching up", but rather at a real "rendez-vous" between regions on both shores.

In any case, if regions on both shores can belong to the same ageing categories in 2065, this means that a region's level of ageing is no longer linked to which shore it lies on. In fact, a change in the spatial dichotomy of the Mediterranean underlies these observations. Analysing the situation by regional trajectory suggests that the north vs. south/east opposition will weaken when it comes to ageing, but it does not allow us to objectively measure this change. To do so, we must harness specific spatial statistics methods to measure the change in the spatial structure of demographic ageing in the Mediterranean. 


\section{TERRITORIES IN AGED CATEGORY IN 2065}

\section{Median scenario}

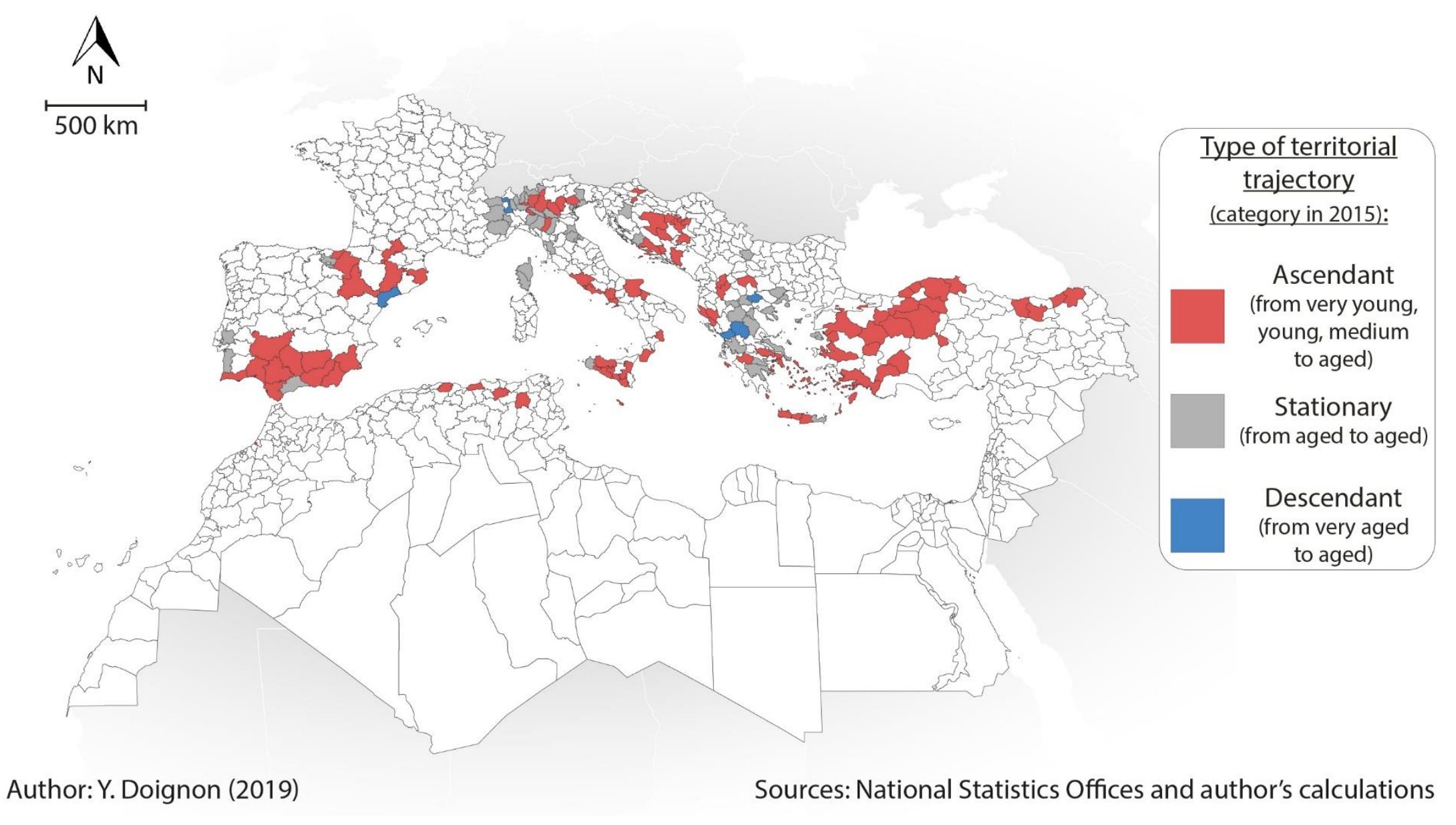

Fig 9: Regions in the "old" category in 2065 according to the median scenario 


\subsection{How will the spatial dichotomy of the Mediterranean evolve?}

\subsubsection{Local changes: spatial convergence and divergence}

The Fig 10 represents the indices of local $\sigma$-convergence. We can see local pockets of spatial convergence and spatial divergence on both the southern and eastern shores and on the northern shore. The areas of spatial convergence are located in Spain, western Turkey, and the southern Balkans (Greece, Albania, Macedonia, Kosovo). They can be explained by certain regions that catch up with their neighbourhood as they age more quickly. The provinces of southeast Spain, for example, are younger than the northwest of the Iberian Peninsula in 2015, but catch up by 2065. The area of spatial convergence in the Balkans can be explained by the faster ageing of the Albanian and Macedonian regions, whose level of ageing approaches that of neighbouring regions.

Areas of spatial divergence can be found on the north Algerian and Tunisian coast, in the Libyan Sahara, in Egypt, in Bulgaria, and in the northern Balkans (Serbia, Bosnia and Herzegovina, Slovenia). These cases of local divergence may be due to regions whose trajectories go against the trajectories of their neighbours. In Bulgaria, for example, many regions are getting younger while all the regions around them get older, whether they are in Turkey, Greece, Macedonia, etc. Spatial divergence can also be explained by demographic ageing happening at differentiated speeds. For example, the area of spatial divergence in the north of Algeria and Tunisia fits the bill here. The entire coast of the Maghreb is ageing, but some coastal regions (identified in the section on regional convergence) are ageing much faster than others. These contrasting developments increase the disparity in the level of ageing between regions at a local level.

These areas of spatial convergence and divergence reflect underlying processes of spatial homogenisation and heterogenisation. Thus, homogeneous zones made up solely of young regions in 2015 can end up heterogeneous (with both young and old regions) by 2065. Some zones which are homogeneous in 2015 are much less so in 2065 (in the northeast of the Maghreb, for example). Conversely, zones can become more homogeneous over time and reinforce existing homogeneity in an area. Some zones converge with one another to a large extent, becoming more homogeneous when they were not necessarily similar in 2015 (e.g. western Turkey with the eastern Balkans). All these changes in local disparities inevitably have an impact on the spatial structure of ageing in the Mediterranean. 


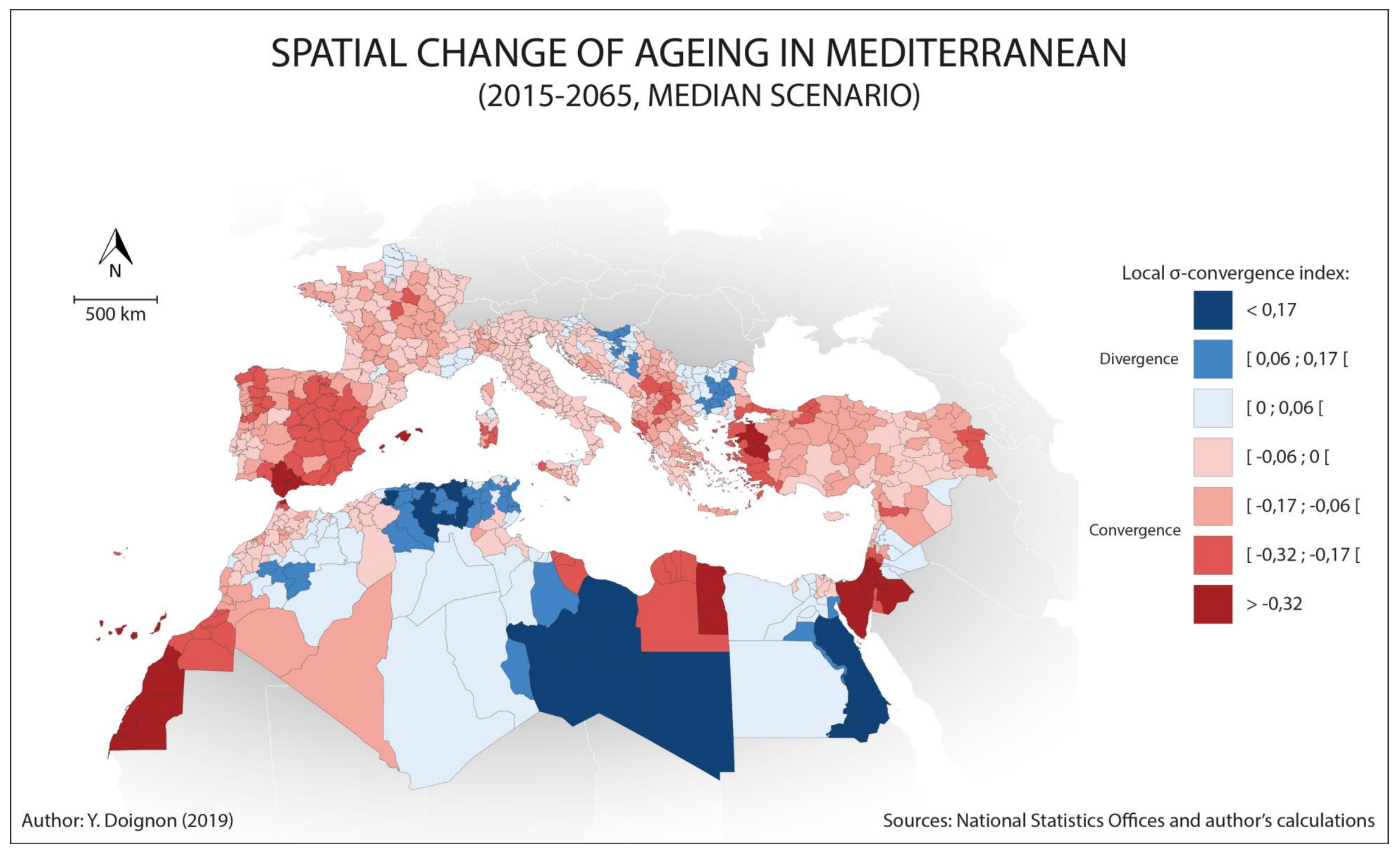

Fig 10: Measurement of local sigma-convergence 


\subsubsection{A changing spatial structure}

In this case, calculating Moran's I confirms that the spatial dichotomy that characterises the Mediterranean in 2015 will become less pronounced. The Moran's I of our ageing indicator is 0.84 in 2015. The value of this index falls until 2065 in all the scenarios, but to different levels: 0.7 for the median scenario, 0.69 for the model transition scenario, 0.79 for the decelerated transition scenario and 0.75 for the rising fertility scenario. If Moran's I increased over time, it would indicate that the spatial dichotomy was becoming more marked.

To conclude, the maps showing the LISA in 2015 and in 2065 (see Fig 11) allow us to assess the evolution of the spatial structure. In 2015, we can clearly identify the geographical opposition between an elderly northern shore (regions in red) and young southern and eastern shores (regions in dark blue). In 2065, on the other hand, the spatial structure is no longer exactly the same: the spatial dichotomy that characterised the Mediterranean in 2015 is not as clear as before. These maps confirm the observations made in previous sections, whereby the regions of the southern and eastern shores are not necessarily the youngest and the regions of the northern shore are no longer necessarily the oldest. In fact, spaces can change category: some regions that were hot spots in 2015 will shift significantly closer to the average by 2065 . This includes, for example, the entire coastline of the Maghreb and Lebanon, regions in Bulgaria and France, and even a large part of the Turkish provinces. We can also see new hot spots emerging in the border region between Croatia and Bosnia and Herzegovina and in western Turkey. 


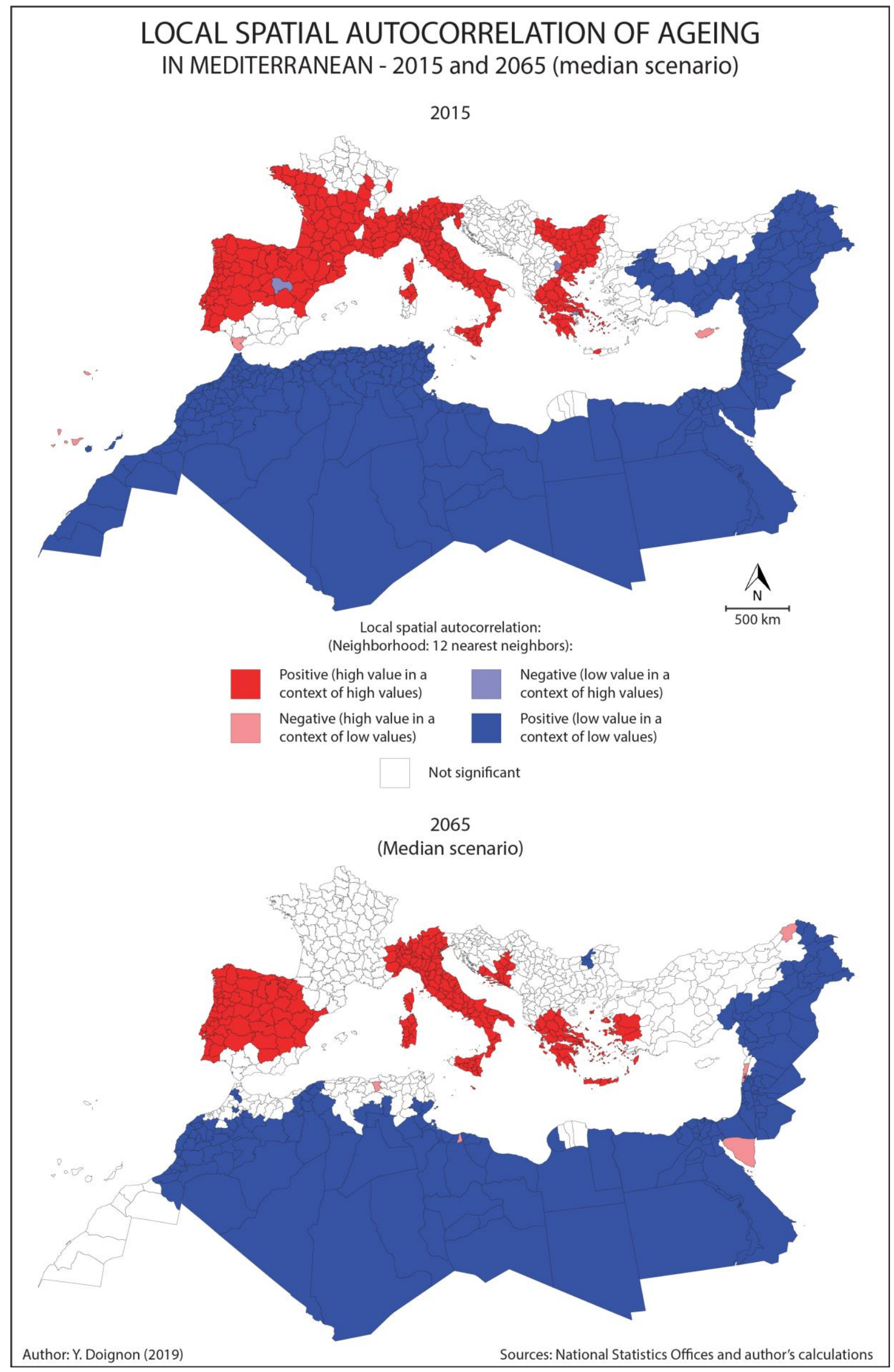

Fig 11: Local Indicator of Spatial Association in 2015 and 2065 


\subsubsection{Limitations of not including migrations in the projections}

The main limitation of our work is that we have not included migration in our projections. Finally, we want to discuss how the results are impacted by this choice.

Migration can strongly influence the ageing of a region's population. Two migratory dynamics are to be considered to discuss our results. First, we rely on the results of the DEMIFER project, which evaluated the impact of migration on the demographic dynamics of European regions between 2005 and 2050 (DEMIFER 2010, 2011). It showed that most migrants belong to the young adult age group. These migrations of young people limit the ageing of their regions of destination and aggravate ageing in their regions of departure. The DEMIFER project has highlighted that the preferred destinations of these migrations are wealthy, accessible and/or regions with pleasant climates. Migration will decrease the ageing of this type of region. Nevertheless, the DEMIFER project focused on European regions in a context of very low fertility. It should be borne in mind that currently the populations of the southern and eastern shores of the Mediterranean do not fall within this context. Some regions have low fertility, but not as low as European levels. In fact, the importance of migration in relation to the natural component must be tempered.

The second migratory dynamic is specific to urban areas. These regions generally have great job opportunities and concentrate wealth. In fact, they attract young populations and expel the oldest individuals from their population. This dynamic strongly limits the demographic ageing of central urban areas and accentuates that of rural or suburban areas. Considering these two migratory dynamics, our study will tend to overestimate the demographic ageing of wealthy, accessible urban areas with a pleasant climate. On the other hand, it underestimates that of poor, inaccessible rural areas with an undesirable climate.

In parallel with these general migratory dynamics, regions may have specific migration profiles. Some Spanish regions attract both young and old people (DEMIFER 2010). Regions of southern France are characterised by a pronounced attraction of elderly people, notably because of heliotropism. These particular migratory dynamics may be at the root of specific ageing trajectories of a region.

Despite this limitation, the relevance and contributions of our study remain intact. Our prospective study sets out the demographic portraits shaped by the natural dynamics of Mediterranean subnational regions. It is a base that international and internal migration will transform more or less intensely. Nevertheless, the quality and availability of migration data make it very difficult to be incorporated in a study like ours. In addition, let us not forget that immigration can only partially offset the impact of ageing and low fertility on the population (DEMIFER 2010, United Nations 2002).

\section{Discussion and conclusion}

The progress of demographic transition in the Mediterranean will mechanically result in an ageing population, but also in the southern and eastern shores catching up to the north shore. By looking at the demographic ageing of the Mediterranean at the subnational level, this article has explored how this process will unfold and has revealed several characteristics.

Today, the southern and eastern shores are in contrast with the northern shore with regards to the level of ageing: the former are young, while the latter is aged. In the future, whatever the scenario, the differences between the Mediterranean shores will be reduced because the southern and eastern shores will catch up with the north shore. In contrast, the southern and eastern shores will partially bridge the gap with respect to the northern shore (to varying extents depending on the scenario), but also that it will not catch up completely.

Despite this partial convergence, it will be possible to locally observe certain areas (or even entire regions) of the southern and eastern shores which will completely catch up with northern shore regions. Thus, subnational regions on both shores will experience similar levels of ageing, 
which is not the case at this time. We have shown that these local trajectories will bring about both convergence and divergence, homogenising certain spaces while revealing spatial heterogeneity in others. As a result, these local convergences and divergences will reduce the current homogeneity within each bank of the Mediterranean. This will have the effect of completely transforming the current North-South spatial dichotomy.

By placing our study at a subnational level, our analysis allows for a different reading of the Mediterranean region than that of the North-South spatial dichotomy. It justifies no longer conceptualising each bank of the Mediterranean as a monolithic block. On the contrary, it highlights regional convergences and spatial dynamics which would have been masked at a national level. This encompasses, for example, the diversity of the ageing rhythms of the southern regions, the specificity of urban regions in relation to rural regions, and the relevance of coastal and hinterland contrasts depending on the country. Our study revealed, in particular, cross-border regions, the spatial organisation of which goes beyond state borders, such as the continuity of the Algerian and Tunisian coastline, or between eastern Turkey and northern Syria.

The main originality of this article is to have produced and analysed demographic projections for subnational regions of the whole Mediterranean. The analysis has become more accurate. The discourse becomes more nuanced with regards to the usual spatial categories. Studies in this field too often use the North-South cleavage framework of interpretation to address social phenomena in the Mediterranean. However, this framework of interpretation is already unsuitable for the studied phenomena, with demographic growth as an example (ITAN 2014a, 2014b). Our work has shown that under the momentum of a process of convergence of ageing between the two shores, the current spatial dichotomy will no longer be an appropriate framework of interpretation to address the youthfulness or ageing of the Mediterranean population (Troisi and Von Kondratowitz 2013). Although the southern and eastern shores will not completely catch up with the northern shore, the overall disparities will be reduced, and regions on both shores will share similar levels of ageing. Following the disappearance of contrasts in fertility and demographic growth rates, the ageing of its population could support the theory that the civilisations of the Mediterranean are destined to come together (Courbage and Todd 2014). By extension, in showing that the Arab-Muslim populations are not destined to remain young, it will offer arguments against the clash of civilisations (Huntington 1993). 


\section{Bibliography}

Al Zalak, Z., \& Goujon, A. (2017). Exploring the fertility trend in Egypt. Demographic Research, 37(32), 995-1030. doi:10.4054/DemRes.2017.37.32

Albera, D. (2006). Anthropology of the Mediterranean: between crisis and renewal. History and Anthropology, 17(2), 109-133. doi:10.1080/02757200600633272

Ambrosetti, E. (2011). Égypte, l'exception démographique. Paris: Institut National d'Études Démographiques.

Ambrosetti, E. (2014). Égypte, la natalité repart à la hausse. Orient XXI. Paris. http://orientxxi.info/magazine/egypte-la-natalite-repart-a-la-hausse,0537

Anselin, L. (1995). Local Indicators of Spatial Association - LISA. Geographical Analysis, 27(2), 93-115. doi:10.1111/j.1538-4632.1995.tb00338.x

Attané, I., \& Courbage, Y. (2001). La démographie en Méditerranée : situation et projections. Paris: Économica.

Avdeev, A., Eremenko, T., Festy, P., Gaymu, J., Bouteillec, N. L., \& Springer, S. (2011). Populations et tendances démographiques des pays européens (1980-2010). Population, 66(1), 9-133.

Béthemont, J. (Ed.). (2001). Le monde méditerranéen: thèmes et problèmes géographiques. Paris: Sedes.

Blok, A., Albera, D., \& Bromberger, C. (Eds.). (2001). L'anthropologie de la Méditerranée. Paris: Maisonneuve et Larose : Maison Méditerranéenne des Sciences de l'Homme.

Bourdin, S. (2013). Une mesure spatiale locale de la sigma-convergence pour évaluer les disparités régionales dans l'Union européenne. Région et Développement, (37), 1-18.

Bourguet, M.-N., Lepetit, B., Nordman, D., \& Sinarellis, M. (Eds.). (1998). L'invention scientifique de la Méditerranée: Egypte, Morée, Algérie. Paris: École des Hautes Etudes en Sciences Sociales.

Braudel, F. (1949). La Méditerranée et le monde méditerranéen à l'époque de Philippe II. Paris: Armand Colin.

Braudel, F. (1977). La Méditerranée, Tome 1: l'espace et l'histoire. Paris: Arts et métiers graphiques.

Bromberger, C., \& Durand, J.-Y. (2001). Faut-il jeter la Méditerranée avec l'eau du bain ? In A. Blok, D. Albera, \& C. Bromberger (Eds.), L'anthropologie de la Méditerranée (pp. 733-756). Paris: Maisonneuve et Larose : Maison Méditerranéenne des Sciences de l'Homme.

Brunet, R. (1995). Modèles de méditerranées. L’Espace géographique, 24(3), 200-202. doi:10.3406/spgeo.1995.3389

Carella, M., \& Parant, A. (2016). Age-structural transition and demographic windows around the Mediterranean. In R. Pace \& R. Ham-Chande (Eds.), Demographic Dividends: 
Emerging Challenges and Policy Implications. Cham: Springer International Publishing. doi:10.1007/978-3-319-32709-9

Chastagnaret, G., \& Ilbert, R. (1991). Quelle Méditerranée? Vingtième Siècle, revue d'histoire, 32(1), 3-6.

Chesnais, J.-C. (1992). The demographic transition: stages, patterns, and economic implications. Oxford; New York: Clarendon Press ; Oxford University Press.

Chesnais, J.-C. (2011). La transition démographique. In F. Meslé, L. Toulemon, \& J. Véron (Eds.), Dictionnaire de démographie et des sciences de la population (pp. 482-483). Paris: Colin.

Courbage, Y. (1997). La démographie en rive sud de la Méditerranée au XXIe siècle: changement de perspectives. Espace Populations Sociétés, 15(1), 11-26. doi:10.3406/espos.1997.1786

Courbage, Y. (1999). Nouveaux horizons démographiques en Méditerranée. Paris: Institut National d'Etudes Démographiques-Presses Universitaires de France.

Courbage, Y. (2008). Démographie des communautés chrétiennes au Proche-Orient. Confluences Méditerranée, 66(3), 27-44. doi:10.3917/come.066.0027

Courbage, Y. (2011). Perspectives du vieillissement démographique au sud de la Méditerranée : aspects démographiques et socio-économiques. Réalités et phantasmes. In W. Molmy, M. Sajoux, \& L. Nowik (Eds.), Vieillissement de la population dans les pays du Sud: famille, conditions de vie, solidarités publiques et privées ... : état des lieux et perspectives. Actes du colloque international de Meknès (pp. 27-29). Paris: CEPED. http://www.documentation.ird.fr/hor/fdi:010054692

Courbage, Y. (2015a). Tunisie: la contre-transition démographique. https://www.youtube.com/watch?v=FBxRclm8wnA

Courbage, Y. (2015b). The political dimensions of fertility decrease and family transformation in the Arab context. DIFI Family Research and Proceedings, 2015(3). doi:10.5339/difi.2015.3

Courbage, Y., \& Todd, E. (2014). A convergence of civilizations: the transformation of Muslim societies around the world. New York: Columbia University Press.

D’Addato, A. (2010). Tendances démographiques, développement économique et mobilité des populations en Méditerranée. Migrations Société, 6(132), 13-30. doi:10.3917/migra.132.0013

DEMIFER. (2010). Demographic and Migratory Flows affecting European Regions and Cities. Final report (p. 96). European Union. ESPON Programme. https://www.espon.eu/sites/default/files/attachments/Final_report_DEMIFER_incl_IS BN_Feb_2011.pdf 
DEMIFER. (2011). Impact of migration on population change. Results from the ESPON DEMIFER Project (Policy Brief) (p. 4). European Union. ESPON Programme. https://www.espon.eu/sites/default/files/attachments/demifer_PB_migr_impact.pdf

Deprest, F. (2002). L'invention géographique de la Méditerranée: éléments de réflexion. L'Espace géographique, 31(1), 73-92. doi:10.3917/eg.311.0073

Deslondes, O. (2004). Les populations des Balkans depuis 1990 : aspects géographiques de la crise. Espace Populations Sociétés, (3), 487-498. doi:10.4000/eps.336

Doignon, Y. (2016). Le vieillissement démographique en Méditerranée: convergences territoriales et spatiales (Ph.D. in Geography). Aix-Marseille University. Retrieved from https://hal.archives-ouvertes.fr/tel-01471133

Doignon, Y., Oliveau, S., \& Blöss-Widmer, I. (2016). L'Europe méridionale depuis 20 ans : dépeuplement, dépopulation et renouveau démographique. Espace Populations Sociétés, (2015/3-2016/1), 23. doi:10.4000/eps.6171

Dollfus, O. (1995). Méditerranées, essai d'analyse géographique. L'Espace géographique, 24(3), 193-199. doi: 10.3406/spgeo.1995.3388

Fargues, P. (1990). Algérie, Maroc, Tunisie : vers la famille restreinte ? Population et Sociétés, (248), 4.

Fargues, P. (1995). Les données démographiques de la paix au Proche-Orient. In L. Blin \& P. Fargues (Eds.), L'économie de la paix au Proche-Orient (pp. 61-90). Maisonneuve et Larose : CEDEJ.

Fargues, P. (2000a). Générations arabes : l'alchimie du nombre. Paris: Fayard.

Fargues, P. (2000b). La démographie et la Méditerranée ou les faits contre les représentations. In E. Kienle (Ed.), La reconstruction d'un espace d'échanges : la Méditerranée (pp. 53-69). CEDEJ - Égypte/Soudan. doi:10.4000/books.cedej.758

Fargues, P. (2006). Afrique du Nord et Moyen-Orient. Politique étrangère, (4), 1017-1029. doi:10.3917/pe.064.1017

Fargues, P., \& Salinari, G. (2011). Flux migratoires et transition démographique. Evolution et scénarios pour l'avenir. In C. Jolly \& "Mediterranean 2030" Consortium (Eds.), Demain, la Méditerranée. Scénarios et projection à 2030 (pp. 71-113). Paris: IPEMED - Institut de prospective économique du monde méditerranéen.

Herzfeld, M. (1987). Anthropology through the looking-glass: critical ethnography in the margins of Europe. Cambridge: Cambridge University Press.

Huntington, S. P. (1993). The clash of civilizations? Foreign Affairs, 72(3), 22-49.

Ilbert, R. (1992). Méditerranée : mer ou continent? Entretien donné à la revue Terres Marines, (4).

ITAN. (2014a). Integrated Territorial Analysis of the Neighbourhoods. ITAN major findingsThe Mediterranean Neighbourhood (No. 8) (p. 4). European Union. ESPON 
Programme.

https://www.espon.eu/sites/default/files/attachments/itan_dossier03_demography.pdf

ITAN. (2014b). Integrated Territorial Analysis of the Neighbourhoods. ITAN major findings From "Migration" to "Mobility" (No. 3) (p. 6). European Union. ESPON Programme. https://www.espon.eu/sites/default/files/attachments/itan_dossier03_demography.pdf

ITAN. (2015). Integrated Territorial Analysis of the Neighbourhoods. Main Report (p. 56). European Union. ESPON Programme. https://www.espon.eu/sites/default/files/attachments/02_ITAN-FRMain_report_FINAL_v15.pdf

Moser, K., Shkolnikov, V., \& Leon, D. A. (2005). World mortality 1950-2000: divergence replaces convergence from the late 1980s. Bulletin of the World Health Organization, 83(3), 202-209. doi:https://doi.org/10.1007/978-1-4020-6174-5_1

Moultrie, T., Dorrington, R., Hill, A., Hill, K., Timaeus, L., \& Zaba, B. (2013). Tools for demographic estimation. Paris: International Union for the Scientific Study of Population.

Oliveau, S., \& Doignon, Y. (2014). Ever closer to the water. Recent developments in Mediterranean settlement patterns. South-East European Journal of Political Science, II(3), 22-30.

Ouadah-Bedidi, Z., Vallin, J., \& Bouchoucha, I. (2012). Unexpected developments in Maghrebian fertility. Population and Societies, (486), 4.

Parant, A., \& Penev, G. (2009). Tendances et différences démographiques dans les Balkans. Estudios Geográficos, LXX(267), 531-565. doi:10.3989/estgeogr.0464

Peristiany, J.-G. (1963). Contributions to Mediterranean sociology. Mediterranean rural communities and social change. In Mediterranean sociological conference (p. 352). Athens: Mouton-EPHE. http://www.cabdirect.org/abstracts/19701803914.html

Peristiany, J.-G. (1966). Honour and shame: the values of Mediterranean society. Chicago: University of Chicago Press.

Peristiany, J.-G. (Ed.). (1976). Mediterranean family structures. Cambridge-London-New York-Melbourne: Cambridge University Press. http://library.wur.nl/WebQuery/clc/349543

Pfirsch, T. (2011). Une géographie de la famille en Europe du Sud. Cybergeo : European Journal of Geography. doi:10.4000/cybergeo.23669

Pina-Cabral, J. de. (1989). The Mediterranean as a category of regional comparison: a critical view. Current Anthropology, 30(3), 399-406.

Pison, G. (2008). L’avenir démographique des pays du Sud. Revue économique, 59(5), 869891. doi:10.3917/reco.595.0869

Pison, G. (2009). Population ageing will be faster in the South than in the North. Population and Societies, 457, 4. 
Preston, S. H. (1975). The changing relation between mortality and level of economic development. Population studies, 29(2), 231-248. doi:10.2307/2173509

Reher, D. S. (2004). The demographic transition revisited as a global process. Population Space and Place, 10(1), 19-41.

Roncayolo, M. (2002). Relire la Méditerranée de Fernand Braudel. In D. Borne \& J. Scheibling (Eds.), La Méditerranée (pp. 216-231). Paris: Hachette.

Sardon, J.-P. (2004). Démographie de pays dans la tourmente : les Balkans depuis 1990. Espace Populations Sociétés, (3), 499-517. doi:10.4000/eps.345

Sebti, M., Courbage, Y., Festy, P., \& Kurzac-Souali, A.-C. (2009). Maghreb, Maroc, Marrakech : convergences démographiques, contrastes socio-économiques. Population et Sociétés, (459), 4.

Shkolnikov, V. M., Andreev, E. M., \& Begun, A. Z. (2003). Gini coefficient as a life table function: computation from discrete data, decomposition of differences and empirical examples. Demographic Research, 8(11), 305-358. doi:10.4054/DemRes.2003.8.11

Tolosana, C. (2001). The ever-changing face of honour. In A. Blok, D. Albera, \& C. Bromberger (Eds.), L'anthropologie de la Méditerranée (pp. 133-147). Paris: Maisonneuve et Larose : Maison Méditerranéenne des Sciences de l'Homme.

Troisi, J., \& Von Kondratowitz, H.-J. (Eds.). (2013). Ageing in the Mediterranean. Bristol: Policy Press.

United Nations (Ed.). (2002). World population ageing, 1950-2050. New York: United Nations.

Wilson, C. (2001). On the scale of global demographic convergence 1950-2000. Population and Development Review, 27(1), 155-171. doi:10.1111/j.1728-4457.2001.00155.x

Wilson, C. (2005). Transitions démographiques en Europe et dans le bassin méditerranéen. In P. Sant Cassia \& T. Fabre (Eds.), Les défis et les peurs : entre Europe et Méditerranée (pp. 21-48). Arles: Paris: Actes Sud - Maison Méditerranéenne des Sciences de l'Homme.

Wilson, C. (2011). Understanding global demographic convergence since 1950. Population and Development Review, 37(2), 375-388. doi:10.1111/j.1728-4457.2011.00415.x

Zagaglia, B. (2013). Transitions démographiques et changements sociaux en région méditerranéenne (p. 3). IEMed. http://www.iemed.org/observatori-fr/areesdanalisi/arxius-adjunts/anuari/iemed-

2013/Zagaglia\%20Transitions\%20Demographiques\%20Mediterranee\%20FR.pdf

\footnotetext{
${ }^{1}$ The notion of "near-equilibrium" is used by Jean-Claude Chesnais (2011) ("quasi-équilibre" in French). This is the equilibrium of the pre-transitional demographic regime. This regime is characterized by zero or very low population growth. Nevertheless, this regime has fluctuations, sometimes significant, in mortality and birth rate, hence the notion of "near-equilibrium".

${ }^{2}$ Data taken from World Population Prospects: the 2015 Revision. https://esa.un.org/unpd/wpp/
} 
${ }^{3}$ We consider all countries with direct access to the Mediterranean Sea to be Mediterranean countries; we also add Portugal, Serbia, Macedonia, Bulgaria and Jordan.

${ }^{4}$ Refer to Doignon (2016) and Chesnais (1992) for more details on the mechanical aspect of the link between aging and demographic transition,

${ }^{5}$ We chose "expectation of life at birth" as an indicator because it provides information on the general state of mortality within a population.

${ }^{6}$ Note the exceptions of Albania, Macedonia, and Bosnia and Herzegovina, whose expectation of life at birth was around 55 years.

${ }^{7}$ We chose not to dwell on this recent rise in fertility, called "counter-transition" by some (Courbage 2015a). The countries concerned are Algeria, Morocco, Tunisia and Egypt (OuadahBedidi et al. 2012, Ambrosetti 2014). Experts have not yet reached a consensus on this issue. It could be due to a cyclical effect linked to the Arab revolutions, a potential return to traditional values, or a number of other factors. In the case of Algeria, one could imagine a post-Civil War effect similar to the baby boom that followed the Second World War, since this rise in fertility has been ongoing for more than 15 years now. Nevertheless, it is unlikely that these rising fertility trends will actually cancel out the sociocultural changes linked to the demographic transition (Courbage 2015b).

${ }^{8}$ The RDMA is a population-weighted relative inequality index obtained by adapting the DMM (Dispersion Measure of Mortality). The methodological details of this index can be found in K. Moser, V. Shkolnikov, D. Leon (2005) and V. Shkolnikov, K. Andreev, A. Begun (2003).

${ }^{9}$ We should specify that the extent to which the southern and eastern shores will catch up with the northern shore depends on the prospective scenario. The effect is quite pronounced in the median scenario and the model transition scenario, and less so in the decelerated transition and rising fertility scenarios. In the last two scenarios, the regions of the southern and eastern shores are over-represented in the "very young" and "young" categories. Compared to the other two scenarios, the regions of the southern and eastern shores are much less likely to share the same ageing category as regions on the northern shore.

10 These regions have either become younger in absolute terms, i.e. their proportion of the population aged 65 or over has decreased, or they have aged more slowly than the Mediterranean average and become relatively younger.

11 For the neighbourhood matrix, we used the 12 closest neighbours. We used this neighbourhood matrix for all the spatial statistics in this section.

${ }^{12}$ For example: Meknes, Salé, Khemisset, Chlef, Oran, Nador, Blida, Mostaganem, Tripoli, Marrakech, Fez, Tangier, Alexandria, Damascus, etc.

${ }^{13}$ With the exception of the two outlying categories ("very young" and "very old"). The former includes almost exclusively regions of the southern and eastern shores, and the latter regions of the northern shore. 